\title{
A 1 1-16 controls synaptic vesicle pools at excitatory synapses via cholinergic modulation of synapsin phosphorylation
}

\author{
Daniela Anni ${ }^{1}$ - Eva-Maria Weiss ${ }^{1}$ - Debarpan Guhathakurta ${ }^{1} \cdot$ Yagiz Enes Akdas ${ }^{1}$. Julia Klueva ${ }^{2} \cdot$ Stefanie Zeitler $^{1}$. \\ Maria Andres-Alonso ${ }^{2} \cdot$ Tobias Huth $^{3} \cdot$ Anna Fejtova $^{1,2}$ (1)
}

Received: 3 September 2020 / Revised: 12 March 2021 / Accepted: 2 April 2021 / Published online: 17 April 2021

(c) The Author(s) 2021

\begin{abstract}
Amyloid beta $(\mathrm{A} \beta)$ is linked to the pathology of Alzheimer's disease (AD). At physiological concentrations, $A \beta$ was proposed to enhance neuroplasticity and memory formation by increasing the neurotransmitter release from presynapse. However, the exact mechanisms underlying this presynaptic effect as well as specific contribution of endogenously occurring $\mathrm{A} \beta$ isoforms remain unclear. Here, we demonstrate that $\mathrm{A} \beta 1-42$ and $\mathrm{A} \beta 1-16$, but not $\mathrm{A} \beta 17-42$, increased size of the recycling pool of synaptic vesicles (SV). This presynaptic effect was driven by enhancement of endogenous cholinergic signalling via $\alpha 7$ nicotinic acetylcholine receptors, which led to activation of calcineurin, dephosphorylation of synapsin 1 and consequently resulted in reorganization of functional pools of SV increasing their availability for sustained neurotransmission. Our results identify synapsin 1 as a molecular target of $A \beta$ and reveal an effect of physiological concentrations of $A \beta$ on cholinergic modulation of glutamatergic neurotransmission. These findings provide new mechanistic insights in cholinergic dysfunction observed in $\mathrm{AD}$.
\end{abstract}

Keywords Amyloid beta $\cdot$ Alpha7 nicotinic acetylcholine receptor $\cdot$ Synaptic vesicle dynamics $\cdot$ Synapsin 1

\section{Introduction}

Amyloid beta peptide $(\mathrm{A} \beta)$ is tightly linked to the pathology of Alzheimer's disease (AD). It forms amyloid plaques, which are an important neuropathological hallmark of $\mathrm{AD}$ [32]. $\mathrm{A} \beta$ arises from proteolytic cleavage of the transmembrane amyloid precursor protein (APP). High mass A $\beta$ species (A $\beta 1-40$ and $A \beta 1-42)$ arise from the amyloidogenic

Eva-Maria Weiss and Debarpan Guhathakurta have contributed equally.

Tobias Huth and Anna Fejtova senior authorship.

Anna Fejtova

Anna.Fejtova@uk-erlangen.de

1 Department of Psychiatry and Psychotherapy, University Hospital, Friedrich-Alexander Universität ErlangenNürnberg, Erlangen, Germany

2 RG Presynaptic Plasticity, Leibniz Institute for Neurobiology, Magdeburg, Germany

3 Institute of Physiology and Pathophysiology, Friedrich-Alexander Universität Erlangen-Nürnberg, Erlangen, Germany proteolytic processing of APP by a combined action of $\beta$ and $\gamma$-secretases $[15,43]$. In the non-amyloidogenic pathway, the cleavage of APP by $\alpha$-secretase and $\gamma$-secretase precludes the generation of high mass $A \beta$ resulting in the liberation of the soluble APP ectodomain (sAPP $\alpha$ ) and P3 peptides (A $\beta 17-40, A \beta 17-42)$ [16]. An alternative pathway, which involves the concerted action of $\alpha$ - and $\beta$-secretases, was identified as source of lower mass peptides covering the $\mathrm{N}$-terminal portion of $\mathrm{A} \beta$ [36]. The most abundant species found in the cerebrospinal fluid (CSF) are the high mass A $\beta 1-40$ and lower mass species containing its N-terminal portion ending around amino acid (aa) 16 [35, 37, 46]. Up to date, most studies in $\mathrm{AD}$ focused on $\mathrm{A} \beta 1-42$, which is relatively low abundant in CSF, but highly prone to aggregation and therefore the seeding component of amyloid senile plaques [20]. In contrast to that, the function of the highly abundant low mass $\mathrm{A} \beta$ fragments and nontoxic $\mathrm{A} \beta$ 1-40 remains less explored.

Over the past decade, it became clear that APP and A $\beta$ possesses central physiological functions in brains. This was supported by the observation that blockade of endogenous $\mathrm{A} \beta$ using specific antibodies as well ablations of APP expression impaired long-term potentiation (LTP) and memory [18, 

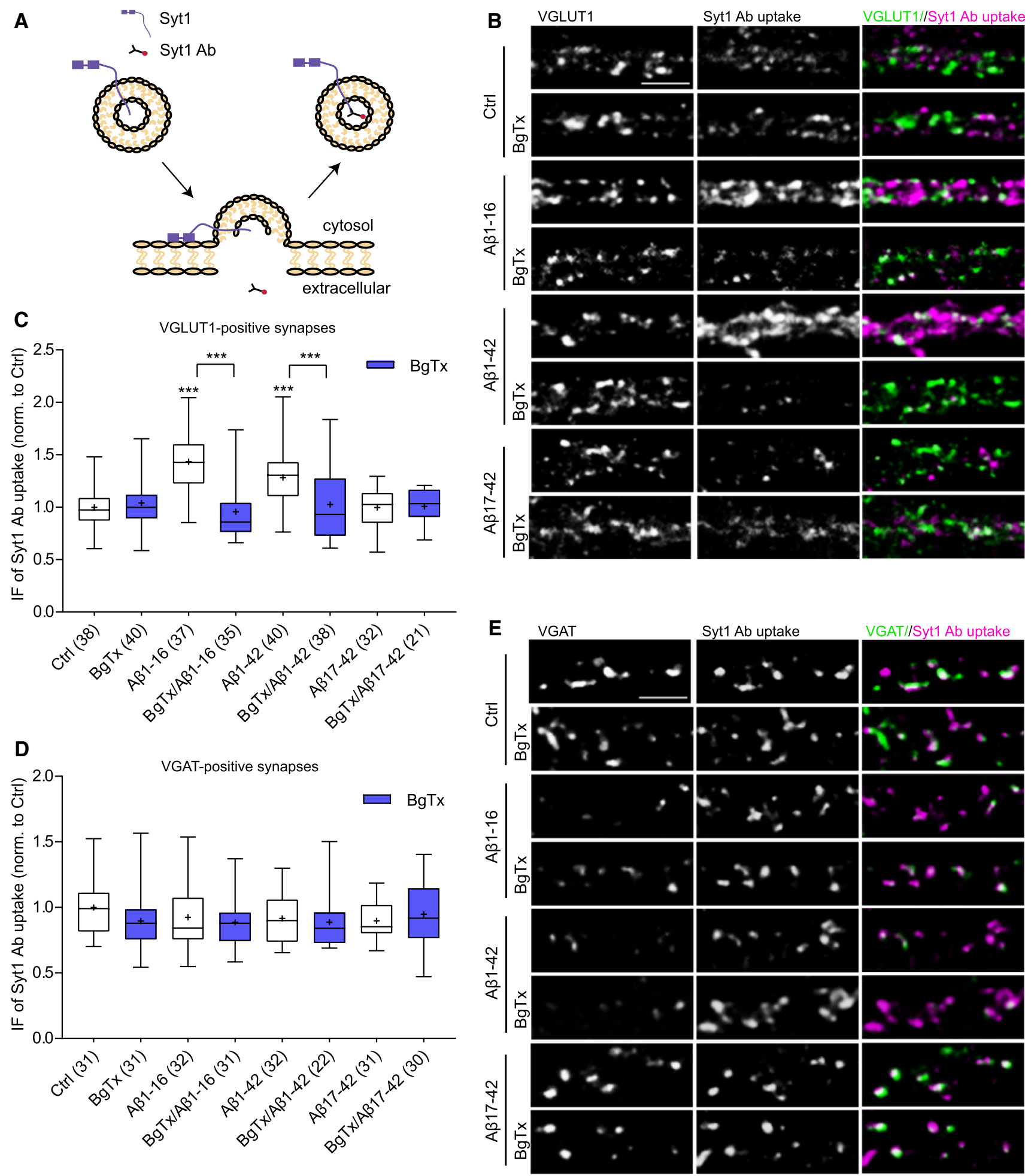

$33,38]$. Thus, the question about possible roles of $\mathrm{A} \beta$ in the regulation of synaptic physiology emerged as a key for understanding the mechanism of AD pathogenesis. A $\beta$ peptides are secreted by neurons in response to neuronal activity and reach concentrations of 200 picomolar (pM) in rodent and human brains $[3,7,23]$. Acute application of 200-300 pM A $\beta 1-42$ increased hippocampal LTP and memory [39], which involves a potentiation of spontaneous and evoked neurotransmitter (NT) release from presynapse [14]. Moreover, an increase of endogenous $\mathrm{A} \beta$ concentrations by interference with normal clearance or an application of pM amounts of synthetic $A \beta 1$ 40 or A $\beta 1-42$ enhanced NT release and recycling of synaptic 
४Fig. 1 The N-terminal domain of A $\beta$ increases the TRP of SVs via $\alpha 7 \mathrm{nAChRs}$ at excitatory but not inhibitory synapses. a Schematic representation of labelling of SV recycling using Syt1 Ab. Upon depolarization, releasable SVs fuse to the plasma membrane. The lumenal domain of integral SV protein Syt1 becomes exposed to the media and available for Syt $1 \mathrm{Ab}$ binding. Compensatory endocytosis drives the uptake of Syt1 Ab inside of retrieved SVs. b, e Representative images of depolarization-induced Syt1 Ab uptake (magenta) in primary cortical neurons (20-21 DIV) treated with vehicle (Ctrl), A $\beta 1$ 16 , A $\beta 1-42$, or A $\beta 17-42$ ( $200 \mathrm{pM}, 1 \mathrm{~h})$ in the presence or absence of BgTx (50 nM, $90 \mathrm{~min})$. Antibody against VGLUT1 and VGAT (green) was used to mark excitatory and inhibitory synapses, respectively. Scale bar is $5 \mu \mathrm{m}$. c, d Quantifications of Syt $1 \mathrm{Ab}$ uptake from $(B, E)$. Values in brackets show the number of analysed cells obtained from two to three independent preparations. In the plots, boxes indicate the interquartile range and median, whiskers minimum and maximum values, and +depicts the mean. One-way ANOVA with Dunnett's post hoc test was used to evaluate statistical significance. Significance of comparison to control are shown about the boxes, the BgTx effects are shown above the brackets; ${ }^{* * *} p<0.001$

vesicles (SVs) in cultured neurons [1, 28]. A contribution of $\alpha 7$ nicotinic acetylcholine receptors ( $\alpha 7 \mathrm{nAChRs})$ was proposed, but remains controversial. Pharmacological interference and genetic ablation of this receptor precluded the effect of $\mathrm{A} \beta 1-42$ on LTP and hippocampal-dependent memory [14, 39]. However, the studies addressing their contribution to the modulation of SV recycling by A $\beta$ came to contradictory conclusions $[10,28]$. Moreover, most recently effects of the low mass $\mathrm{N}$-terminal A $\beta$ fragments and/or the secreted APP $\alpha$ fragments containing the $\mathrm{N}$-terminal $\mathrm{A} \beta$ portion on neuroplasticity and cognition were described, which were linked to $\alpha 7 \mathrm{nAChRs}$ and proposed its presynaptic site of action [18, 27, 40]. These data indicate that the physiological function of the full length $\mathrm{A} \beta$ may reside in its $\mathrm{N}$-terminal portion, however, a systematic comparison of these $\mathrm{A} \beta$-derived fragments at the presynaptic level has not been performed yet.

Thus, in this study, we dissected effects of $\mathrm{A} \beta 1-42$ and its $\mathrm{N}$ - and C-terminal fragments on $\mathrm{SV}$ recycling. We show that the $\mathrm{N}$-terminal fragment, $\mathrm{A} \beta 1-16$, but not the $\mathrm{C}$-terminal $A \beta 17-42$ holds all regulatory effects of A $\beta 1-42$. Using pharmacological and genetic approaches, we confirm a key role of $\alpha 7 \mathrm{nAChRs}$ in this process and postulate that $\mathrm{A} \beta 1-16$ acts as a positive allosteric modulator of these receptors. Moreover, we identified the activation of phosphatase calcineurin and consequent dephosphorylation of synapsin 1 (Syn1) as a molecular mechanism underlying the increased SVs mobilization and availability upon A $\beta 1-16$ application. Thus, we propose that physiologically occurring A $\beta 1-16$ enhances cholinergic modulation of glutamatergic presynapse.

\section{Results}

\section{A $\beta$ 1-16 increases recycling of SVs at glutamatergic synapses}

We have shown previously that modulation of extracellular levels of endogenous $A \beta$ affects recycling of SVs [28]. To gain further insights into the mechanisms behind the regulation of NT release, we monitored SV recycling in living rat cortical neurons. To this end, we used a fluorescently labelled anti-synaptotagmin 1 antibody (Syt1 Ab), which was directed against the lumenal domain of this SV protein. Once added to the media, this antibody internalizes and labels SVs during their fusion with the plasma membrane (Fig. 1a), and thus the amount of SVs that undertook exo-/ endocytic cycles can be approximated by the uptaken immunofluorescence (IF) at individual synapses [25, 28]. To label the total recycling pool of SVs (TRP), we induced exocytosis of all releasable vesicles by a brief (4 min) application of depolarizing media. We quantified the TRP in neurons pretreated with vehicle or with solution containing synthetic A $\beta 1-16$, A $\beta 1-42$, or $A \beta 17-42$ peptides for $1 \mathrm{~h}$. First, we assessed individual excitatory synapses that were labelled post hoc using an antibody against the vesicular glutamate transporter-1 (VGLUT1). The observed Syt1 Ab uptake was significantly increased in cells treated with $200 \mathrm{pM} A \beta 1$ 16 and $A \beta 1-42$ compared to vehicle-treated cells (Fig. 1b,c; $\mathrm{A} \beta 1-16: 1.43 \pm 0.05$; $\mathrm{A} \beta 1-42$ : $1.28 \pm 0.04$; Ctrl: $1 \pm 0.03$ ). To evaluate a possible requirement of $\alpha 7 \mathrm{nAChRs}, 50 \mathrm{nM}$ of a selective $\alpha 7 \mathrm{nAChR}$ antagonist $\alpha$-Bungarotoxin (BgTx) was applied $30 \mathrm{~min}$ before and during $A \beta$ treatments. While BgTx alone had no effect on Syt1 Ab uptake in non-treated cells (Fig. 1b,c; BgTx: $1.04 \pm 0.04$ ), it interfered with the effect of both A $\beta 1-16$ and A $\beta 1-42$ (Fig. 1b,c; BgTx/A $\beta 1-16$ : $0.96 \pm 0.04 ; \mathrm{BgTx} / \mathrm{A} \beta 1-42: 1.03 \pm 0.05)$. Interestingly, application of $A \beta 17-42$ had no effect in presence or in absence of BgTx (Fig. 1b,c; A $\beta 17-42: 0.99 \pm 0.03$; BgTx/A $\beta 17-42$ : $1 \pm 0.03$ ). Next, we assessed TRP in GABAergic synapses that were identified using an antibody against the vesicular GABA transporter (VGAT). None of A $\beta$-derived peptides affected GABAergic SV recycling (Fig. 1d,e; Ctrl: $1 \pm 0.04$; BgTx: $0.90 \pm 0.03 ; \mathrm{A} \beta 1-16: 0.92 \pm 0.04 ; \mathrm{BgTx} / \mathrm{A} \beta 1-16$ : 0.88 \pm 0.03 ; А $\beta 1-42: 0.92 \pm 0.03$; BgTx/A $\beta 1-42: 0.89 \pm 0.04$; A $\beta 17-42: 0.90 \pm 0.03 ; \mathrm{BgTx} / \mathrm{A} \beta 17-42: 0.95 \pm 0.04)$. Thus, these data constitute the $\mathrm{N}$-terminal amino acids (aa) 1-16 of A $\beta 1-42$ as the active epitope sufficient and necessary to regulate presynaptic recycling. Moreover, they indicate a role for $\alpha 7 \mathrm{nAChR}$ in A $\beta$-mediated effect on TRP at excitatory, but not at inhibitory synapses.

To get a direct readout of basal synaptic transmission, we recorded AMPA receptor-mediated miniature postsynaptic currents (mEPSC) using whole-cell voltage-clamp 
A

mEPSC

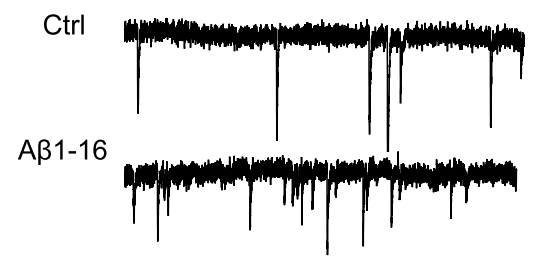

$A \beta 1-16+B g T x$

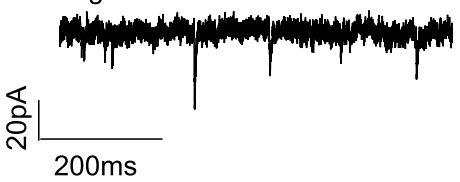

C
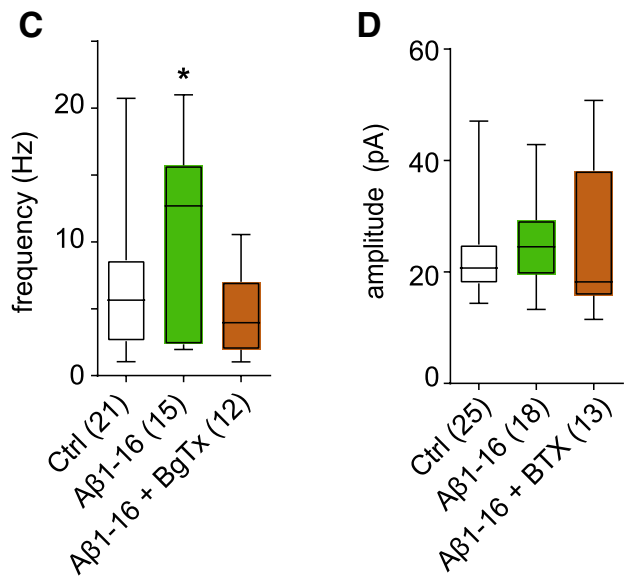

G

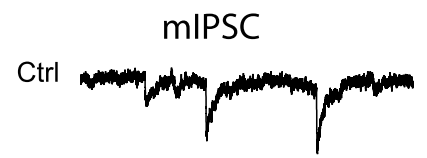

$A \beta 1-16$

잉 $250 \mathrm{~ms}$

I

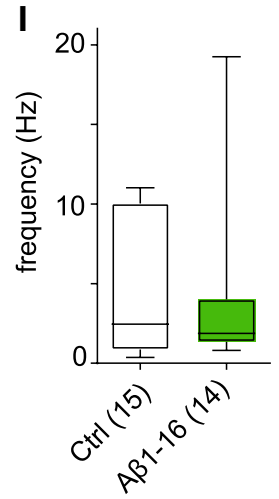

J

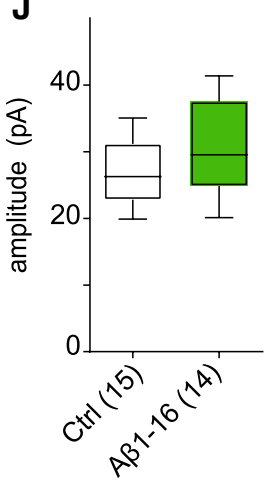

B

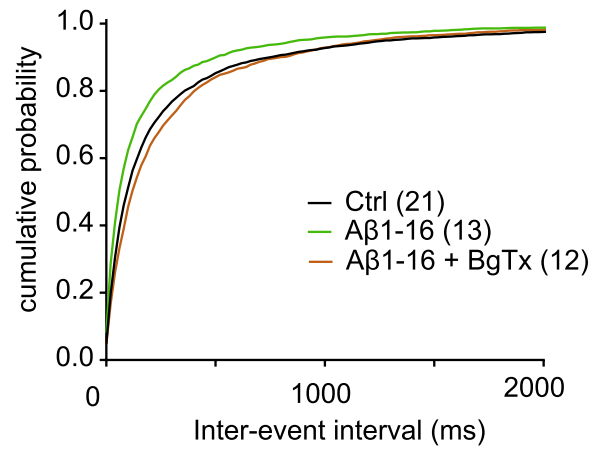

E

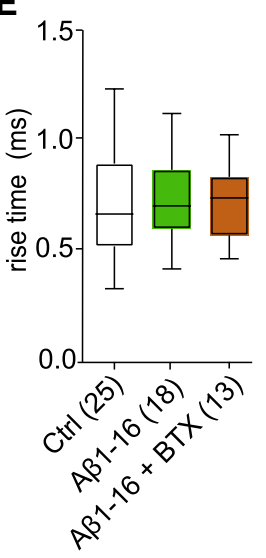

F
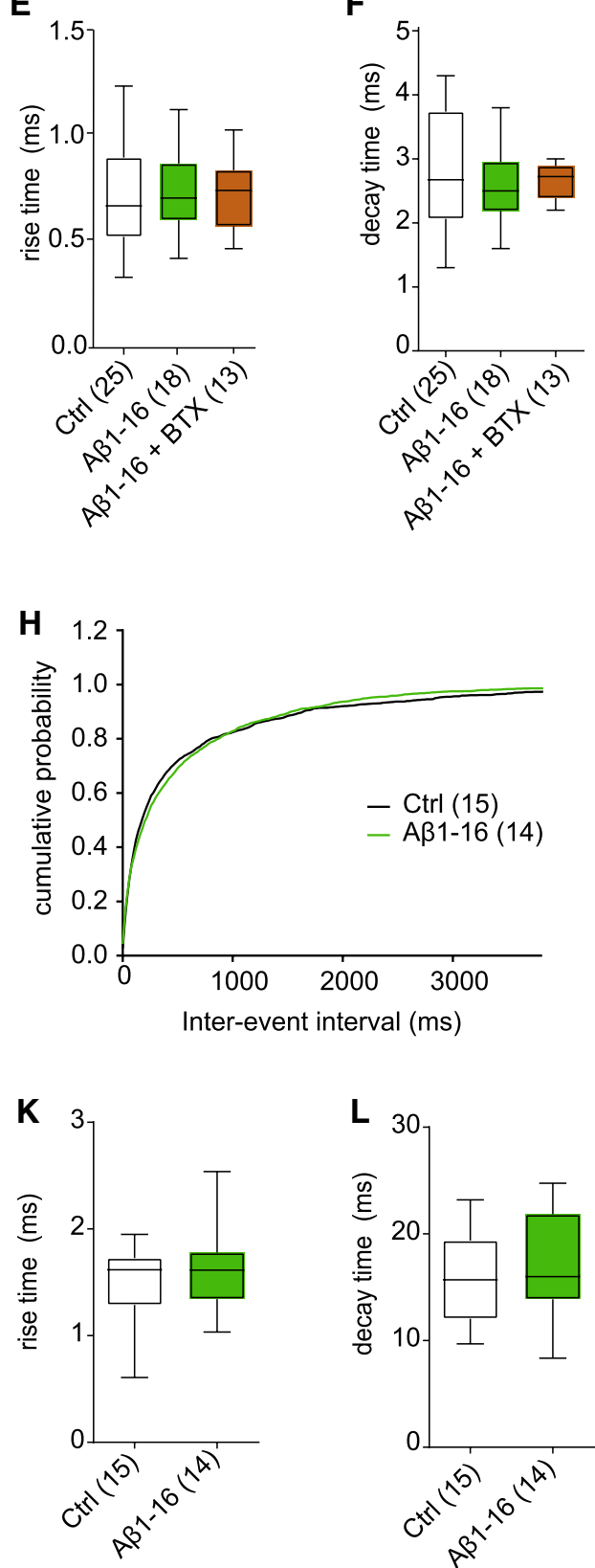
4 Fig. 2 Effect of A $\beta 1-16$ on mEPSCs and mIPSC in hippocampal neurons. a Examples of mEPSC traces recorded in neurons under control conditions and after incubation with the A $\beta 1-16$ alone or in presence of BTX (b). Cumulative distributions of the inter-event intervals of mEPSC from the experiment in a. Fragment A $\beta 1-16$ significantly decreased mEPSC inter-event intervals, which is reflected in leftward shift of the cumulative distribution compared to control or A $\beta+$ BTX $(\mathrm{p}<0.001$, Kolmogorov-Smirnov test). A $\beta 1-16$ increases mean frequency (c), without effect on amplitude (d), rise time (e) and decay time (f) of mEPSC. Treatment with BgTx counteracts this effect. g Examples of mIPSC traces recorded in control neurons and after incubation with the A $\beta 1-16$. $\mathbf{h}$ Cumulative distributions of the interevent intervals of mIPSC in control neurons and after application of $\mathrm{A} \beta 1-16$. A $\beta 1-16$ fragment has no effect on the mean frequency (i) amplitude (j), rise (k) and decay time (l) of mIPSC. Values in brackets in B-F and in $\mathrm{H}-\mathrm{L}$ are number of analysed cells obtained from three independent preparations. Data are displayed as means $(\mathbf{b}, \mathbf{h})$ or as means $\pm \operatorname{SEM}(\mathbf{c}-\mathbf{l}),{ }^{*} \mathrm{p}<0.05$ compared to control, $t$ test

recordings in cultured hippocampal neurons (Fig. 2a). Application of A $\beta 1-16$ (200 $\mathrm{pM}) 1 \mathrm{~h}$ prior to recording significantly increased the mEPSC frequency without changing the current amplitude, rise time or decay time (Fig. 2bf; frequency (Hz): Ctrl 6.48 \pm 1.14 , A $\beta 1-1610.78 \pm 1.73$; amplitude (pA): Ctrl: $22.57 \pm 1.66$; A $\beta 1-16: 23.81 \pm 1.67$; rise $t(\mathrm{~ms}):$ Ctrl: $0.81 \pm 0.07, \mathrm{~A} \beta 1-16: 0.73 \pm 0.04$; decay $t(\mathrm{~ms})$ Ctrl: $2.80 \pm 0.19$, A $\beta 1-16: 2.56 \pm 0.14)$. An application of $\operatorname{BgTx}(50 \mathrm{nM}, 30 \mathrm{~min}$ before and during A 1 1-16 application) completely abolished the effect of $A \beta 1-16$ on the mEPSC frequency indicating the involvement of $\alpha 7 \mathrm{nAChR}$ (Fig. 2a-f; A $\beta 1-16+\mathrm{BgTx}$ : frequency $4.78 \pm 0.94 \mathrm{~Hz}$; amplitude $23.73 \pm 3.47 \mathrm{pA}$; rise $t$ $0.71 \pm 0.04 \mathrm{~ms}$; decay t $2.66 \pm 0.12 \mathrm{~ms}$ ). Next we examined the effect of A $\beta 1-16$ on GABA receptor-mediated miniature inhibitory postsynaptic currents (mIPSCs) (Fig. 2g). None of the analysed parameters differed between treated cells and controls indicating that $A \beta 1-16$ does not affect GABA-ergic transmission (Fig. $2 \mathrm{~h}-1$; frequency $(\mathrm{Hz})$ : Ctrl 4.23 \pm 1.09 , A $\beta 1-16$ 3.86 \pm ; 1.59 ; amplitude (pA): Ctrl: $26.76 \pm 1.22 ; \mathrm{A} \beta 1-16: 30.52 \pm 2.23$; rise $\mathrm{t}(\mathrm{ms})$ : Ctrl: $1.48 \pm 0.11$, A $\beta 1-16: 1.62 \pm 0.11$; decay $t(\mathrm{~ms})$ Ctrl: $16.05 \pm 0.99, \mathrm{~A} \beta 1-16: 17.54 \pm 1.41)$. These support the notion that $A \beta 1-16$ affect specifically neurotransmission at excitatory synapses and indicate an involvement of $\alpha 7 \mathrm{nAChR}$ in this process.

\section{a7nAChRs are required for $A \beta$-mediated increase in recycling of SVs}

To further substantiate the requirement of $\alpha 7 \mathrm{nAChRs}$ for $A \beta$-mediated increase in TRP, we tested the effect of $A \beta$ in neurons with genetic ablation of these receptors. For this purpose, we cultured cortical neurons derived from Chrna $7^{\text {flox/flox }}$ mice having exon 4 of Chrna7 gene (encoding $\alpha 7 n A C h R$ ) flanked by lox P sites (Fig. S1A). In these neurons, the expression of functional $\alpha 7 \mathrm{nAChR}$ declined upon infection with nuc-EGFP-cre-recombinase (CRE $=$ CHRNA7 $\mathrm{KO}$ ) expressing lentiviruses. Cells infected with a lentivirus expressing an inactive form of nuc-EGFP-cre-recombinase $(\triangle \mathrm{CRE}=$ WT, Figs. S1 A, Fig. 2a) were used as control. The efficiency of exon excision was confirmed by qPCR (Fig S1).

Both control (WT) and $\alpha 7 \mathrm{nAChRs-depleted} \mathrm{cultures}$ (CHRNA7 KO) showed a comparable size of TRP under basal conditions (Fig. 3b,c; WT: $1 \pm 0.10$, CHRNA7 KO: $0.96 \pm 0.06$ ). Treatment with $200 \mathrm{pM} \mathrm{A} \beta 1-42$ and $\mathrm{A} \beta 1-16$ for $1 \mathrm{~h}$ resulted in an increased TRP in WT (Fig. 3b,c; WT/ A $\beta 1-16: 1.27 \pm 0.06$; WT/A $\beta 1-42: 1.21 \pm 0.08)$, but had no effect on CHRNA7 KO cultures (Fig. 3b,c; CHRNA7 KO/ A $\beta 1-16: 0.99 \pm 0.05$; CHRNA7 KO/A $\beta 1-42: 0.86 \pm 0.05$ ). These results confirm that the regulation of TRP by A $\beta$ depends on $\alpha 7 \mathrm{nAChRs}$.

\section{A $\beta$ 1-16 modulates nicotine-induced $\mathrm{Ca}^{2+}$ influx through a7nAChRs}

In the course of our experiments, we observed that neurons treated with $A \beta 1-16$ or $A \beta 1-42$ in culture media showed a robust increase of TRP, but cells from the same batch that were washed and transferred to fresh Tyrode's buffer (TB) before treatment with the A $\beta 1-16$ peptide failed to increase their TRP (Fig. 4a,b; A $\beta 1-16: 1.39 \pm 0.08$; $A \beta 1-16 /$ TB: $1.09 \pm 0.06$; Ctrl: $1 \pm 0.05$ ). Intriguingly, our neuronal growth medium contains physiological concentration of choline $(28 \mu \mathrm{M})$, a selective endogenous agonist of $\alpha 7 \mathrm{nAChRs}$ [2]. Thus, we decided to assess whether choline is required for A $\beta 1-16$-induced regulation of TRP in our system. The Syt1 Ab uptake was not different in cells pre-incubated for $1 \mathrm{~h}$ in TB or in TB supplemented with choline (Fig. 4a,b; TB: $0.98 \pm 0.06$; $\mathrm{TB}+$ choline: $1.22 \pm 0.06$ ). The treatment of cells with A $\beta 1-16$ had no effect on TRP in TB, but cells treated with $A \beta 1-16$ in the presence of choline showed a robust increase in TRP (Fig. 4a,b; A $\beta 1-16 / T B+$ choline: $1.73 \pm 0.11)$. This indicates that A $\beta 1-16$ likely acts as a positive allosteric modulator of $\alpha 7 \mathrm{nAChRs}$ rather than an agonist.

To test this hypothesis and given the high $\mathrm{Ca}^{2+}$ permeability of $\alpha 7$ nAChRs [5, 42], we performed a fluorescentbased $\mathrm{Ca}^{2+}$ imaging assay in HEK293T cells expressing $\alpha 7 \mathrm{nAChRs}$ and TMEM35A (NACHO), an accessory protein necessary for their efficient surface expression [13]. Cells were loaded with the $\mathrm{Ca}^{2+}$-sensitive fluorescent dye Cal$520 \mathrm{AM}$ and recorded using a fluorescent microplate reader. Brief application of both $A \beta 1-16$ and $A \beta 1-42$ produced no changes in fluorescence per se, but significantly enhanced the $\mathrm{Ca}^{2+}$ influx induced by application of $100 \mu \mathrm{M}$ nicotine (Fig. 4c,d; A $\beta 1-16: 1.37 \pm 0.06$; A $\beta 1-42: 1.28 \pm 0.07$; Ctrl: $1 \pm 0.05)$. In contrast, application of $A \beta 17-42$ had no effect alone and also did not affect the response to nicotine injection (Fig. 4c,d; A 117-42: 1.08 \pm 0.07 ). Taken together, these 
A
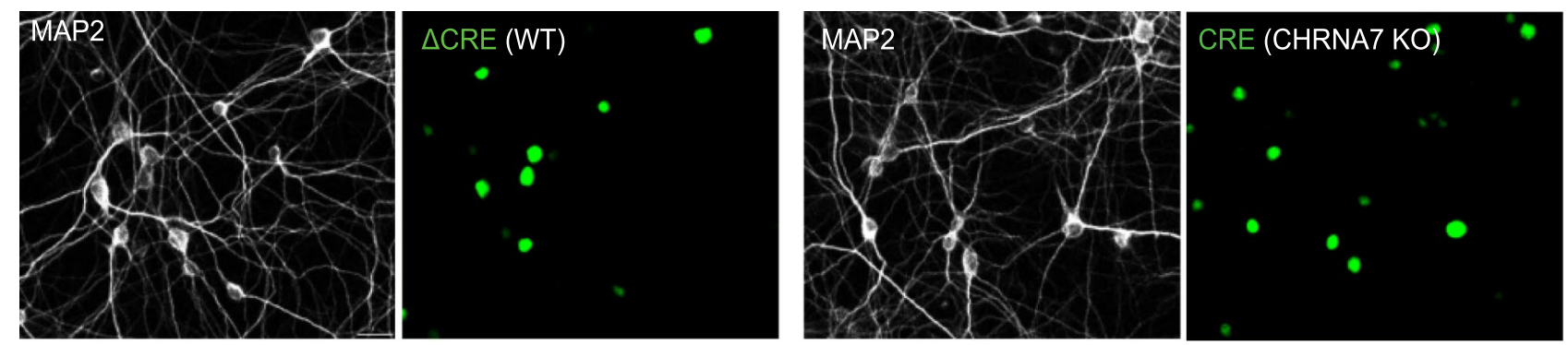

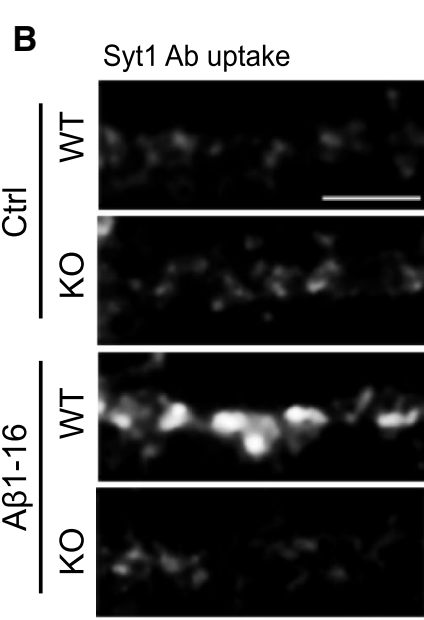

VGLUT1

\section{B}

Syt1 Ab uptake
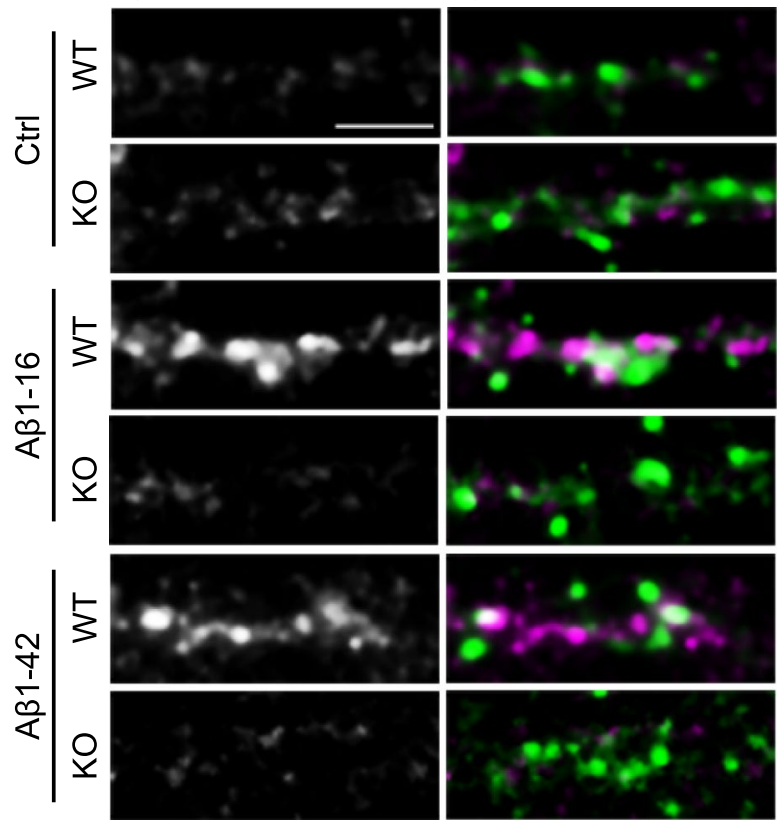

Fig. 3 A $\beta$ 1-16-mediated increase in SV recycling requires normal expression of $\alpha 7 \mathrm{nAChRs}$. a Representative images of primary mouse neurons (16 DIV) infected at 4 DIV either with $\triangle$ CRE (WT) or CRE (CHRNA7 KO) and stained with MAP2 to assess neuronal transduction efficiency. Scale bar $20 \mu \mathrm{m}$. b Images show the Syt1 Ablabelled TRP in cortical mouse cultures (16-17 DIV) pretreated with vehicle (Ctrl), A $\beta 1-16$, or A $\beta 1-42$ on the left (magenta) at excitatory presynapses marked with VGLUT1 (green). Scale bar $5 \mu \mathrm{m}$. c Quan-

results indicated that the $\mathrm{N}$-terminal but not the $\mathrm{C}$-terminal part of $\mathrm{A} \beta 1-42$ acts as a potent allosteric modulator of $\alpha 7$ nAChRs enhancing nicotine-induced $\mathrm{Ca}^{2+}$ influx.

\section{A $\beta 1-16$ modulates nicotine-induced inward current of $\alpha 7 n A C h R s$}

The modulation of $\alpha 7 \mathrm{nAChRs}$ by $\mathrm{N}$-terminal fragment of $A \beta$ was further examined by whole-cell patch-clamp recordings of nicotine-induced $\alpha 7 \mathrm{nAChRs-mediated} \mathrm{cur-}$ rents in HEK293T cells. In this experimental setup, a brief puff application of nicotine reproducibly induced inward

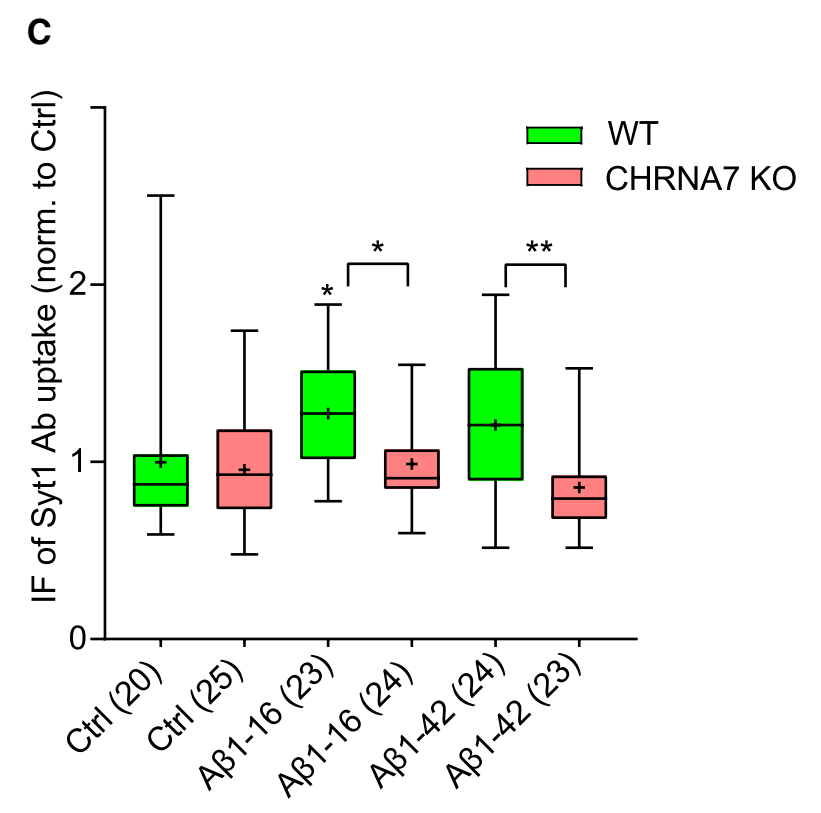

tification of the IF intensity of Syt1 Ab uptake shown in $\mathbf{b}$. Values in brackets indicate the number of analysed cells obtained from two independent experiments. Boxes indicate the interquartile range and median, whiskers minimum and maximum values, and + shows the mean. One-way ANOVA followed by Tukey's post hoc test was used to assess statistical significance. The comparisons to vehicle-treated WT neurons are above each box, the symbols above brackets indicate the effect of CHRNA7-depletion, ${ }^{*} p<0.05$, ${ }^{*} p<0.01$

currents, while application of A $\beta 1-16$ (200 pM, $300 \mathrm{ms,}$ 2 bar) had no effect (Fig. 5a).

However, if nicotine was applied in presence of $\mathrm{A} \beta 1$ 16 the evoked inward currents had a significantly higher peak current amplitude (Fig. 5a,b; A $\beta 1-16$ : $-1471 \pm 156$ pA; Ctrl: $-594 \pm 116$ pA). Conversely, the current peak amplitude evoked by nicotine remained unchanged in presence of the C-terminal $A \beta 17-42$ peptide confirming no modulation of $\alpha 7 \mathrm{nAChRs}$ by the $\mathrm{C}$-terminal fragment of $A \beta$ (Fig. $5 \mathrm{a}, \mathrm{b} ; \mathrm{A} \beta 17-42:-680 \pm 100 \mathrm{pA}$ ). The kinetics of nicotine-induced currents did not significantly differ between treatments. Under all conditions, currents reached their peak within about $100 \mathrm{~ms}$ (Fig. 5a,c; Ctrl: 

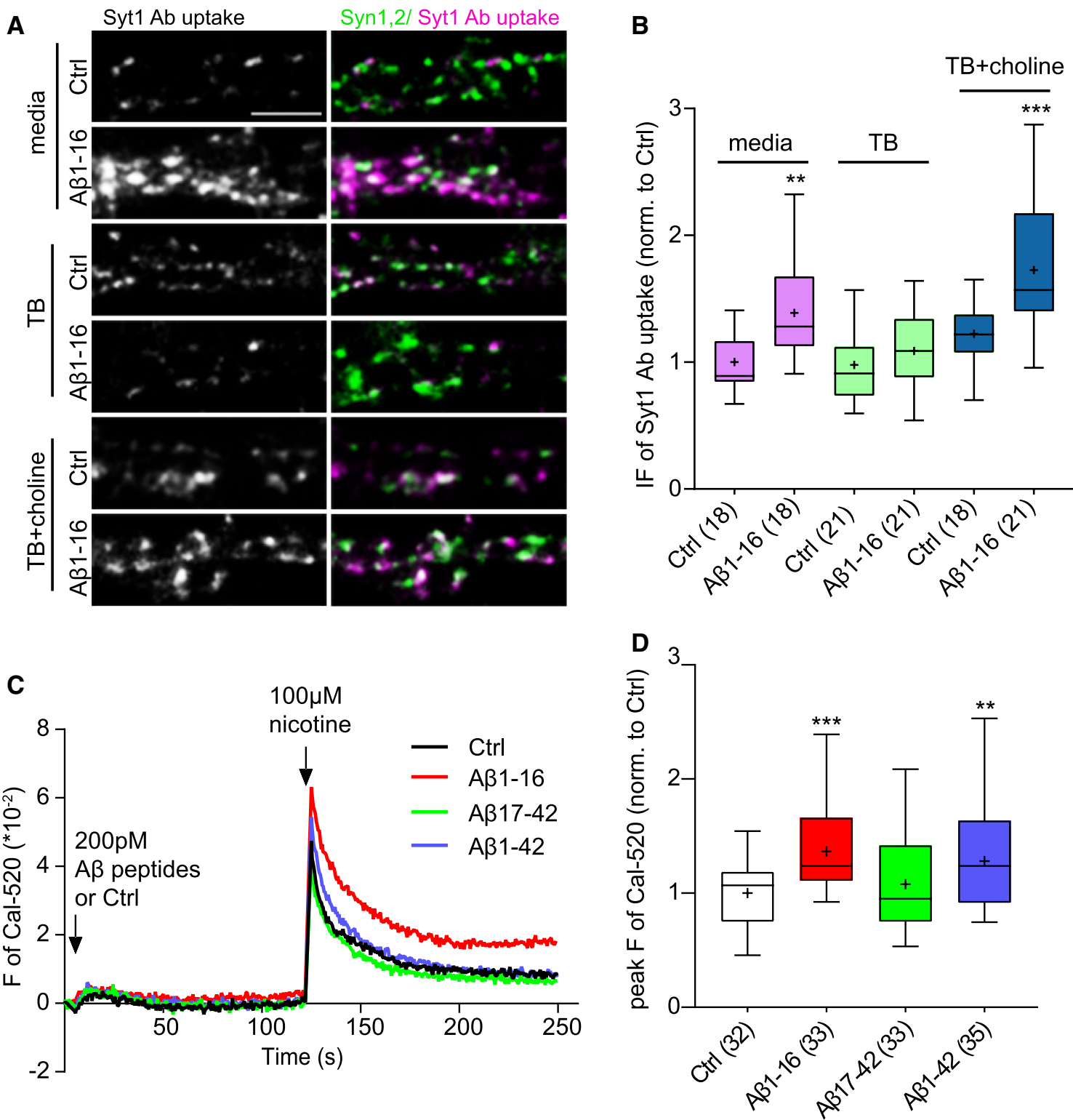

Fig. $4 \mathrm{~N}$-terminal portion of $\mathrm{A} \beta$ requires choline and nicotine to increase TRP and $\mathrm{Ca}^{2+}$ influx via $\alpha 7 \mathrm{nAChRs}$. a Images show TRP labelled by Syt $1 \mathrm{Ab}$ loading (magenta) in rat cortical neurons treated either with vehicle or 200 pMA $\beta 1-16\left(1 \mathrm{~h}, 37^{\circ} \mathrm{C}\right)$ in the neuronal growth media, in Tyrode's buffer or in Tyrode's buffer supplemented with $28 \mu \mathrm{M}$ choline. Synapses were identified by co-staining for Syn1,2 (green). Scale bar $5 \mu \mathrm{m}$. b Quantification of the experiment described in a. $\mathrm{c} \mathrm{Ca}^{2+}$ imaging was done using Cal-520 AM indicator in HEK293T expressing $\alpha 7 \mathrm{nAChRs}$. Traces show the time course of the experiment. Arrows depict the sequential applications of human

$102 \pm 8 \mathrm{~ms} ; \mathrm{A} \beta 1-16: 101 \pm 9 \mathrm{~ms} ; \mathrm{A} \beta 17-42: 92 \pm 10 \mathrm{~ms})$ followed by exponentially current decay with a similar fast and slow time constant $(\tau)$ (Fig. $5 \mathrm{a}, \mathrm{d}, \mathrm{e} ; \tau_{\text {fast }}$ : Ctrl: $79 \pm 9 \mathrm{~ms} ; \mathrm{A} \beta 1-16: 63 \pm 5 \mathrm{~ms} ; \mathrm{A} \beta 17-42: 63 \pm 47 \mathrm{~ms} ; \tau_{\text {slow }}$ : Ctrl: $3320 \pm 410 \mathrm{~ms} ; A \beta 1-16: 2750 \pm 120 \mathrm{~ms} ; \mathrm{A} \beta 17-42$ : $2950 \pm 330 \mathrm{~ms}$ ), indicating that $\mathrm{A} \beta 1-16$ did not affect channel kinetics. Thus, the N- and not the C-terminal
A $\beta 1-16$, human/rat A $\beta 17-42$, human A $\beta 1-42(200 \mathrm{pM}, 115 \mu \mathrm{l} / \mathrm{s})$ or vehicle solution and nicotine $(100 \mu \mathrm{M}, 115 \mu \mathrm{l} / \mathrm{s})$. d Quantification of nicotine-induced Cal-520 fluorescence in experiment shown in graph (C). Values in brackets refer to the number of analysed cells (b) or recorded wells (d) obtained from two (b) or four (D) independent preparations. Boxes indicate the interquartile range with median, whiskers minimum and maximum values, and + shows the mean. Significance was assessed by one-way ANOVA followed by Dunnett's post hoc test; marks $(* * * p<0.001, * * p<0.01)$ above boxes indicate comparisons to the $\mathrm{Ctrl}$

domain of $A \beta 1-42$ acts as a positive allosteric modulator type I of $\alpha 7 \mathrm{nAChRs}$ increasing peak amplitude of nicotine evoked currents but not its desensitization. 


\section{A}

Aß1-16 puff
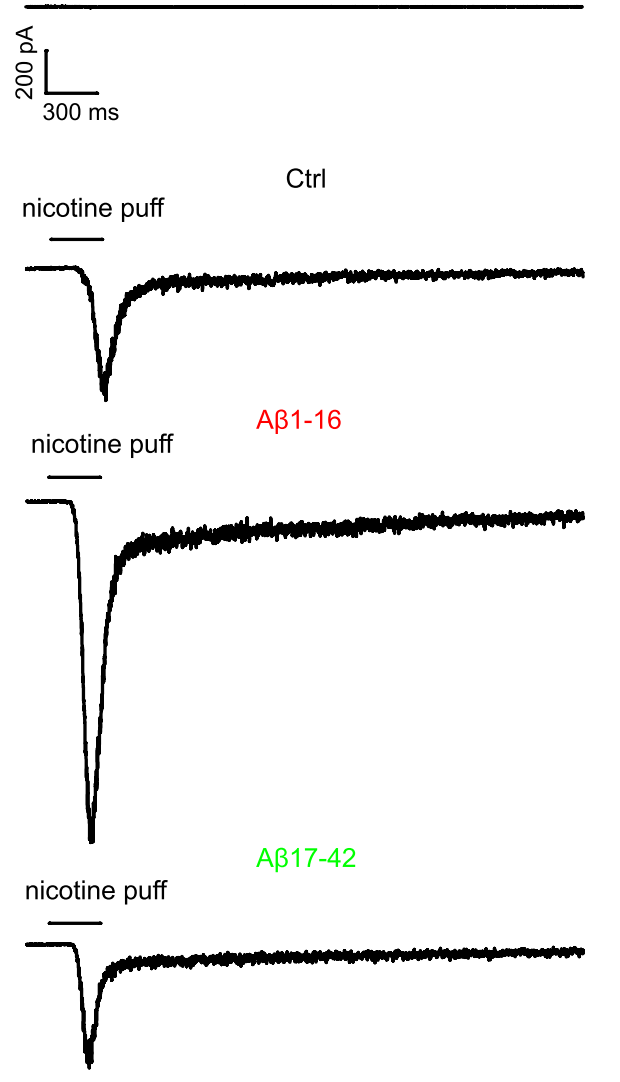

B
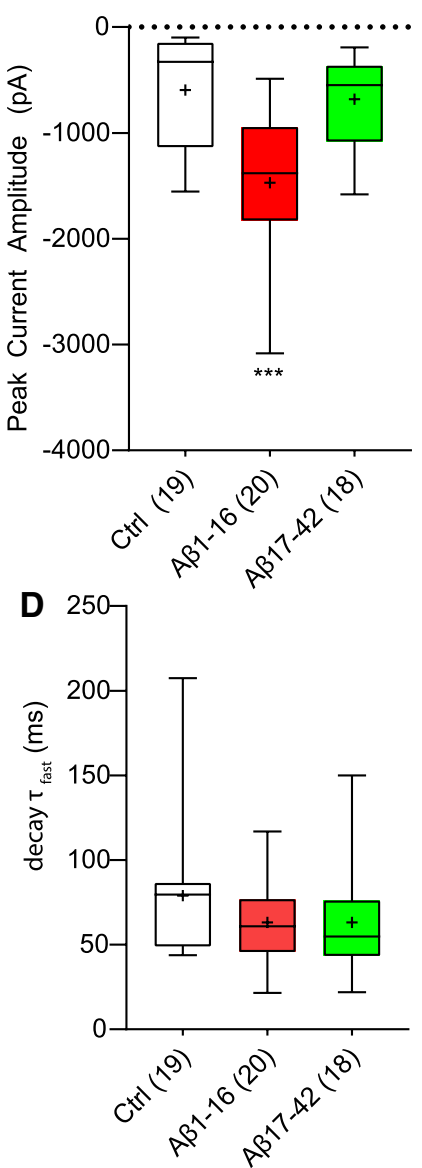

C

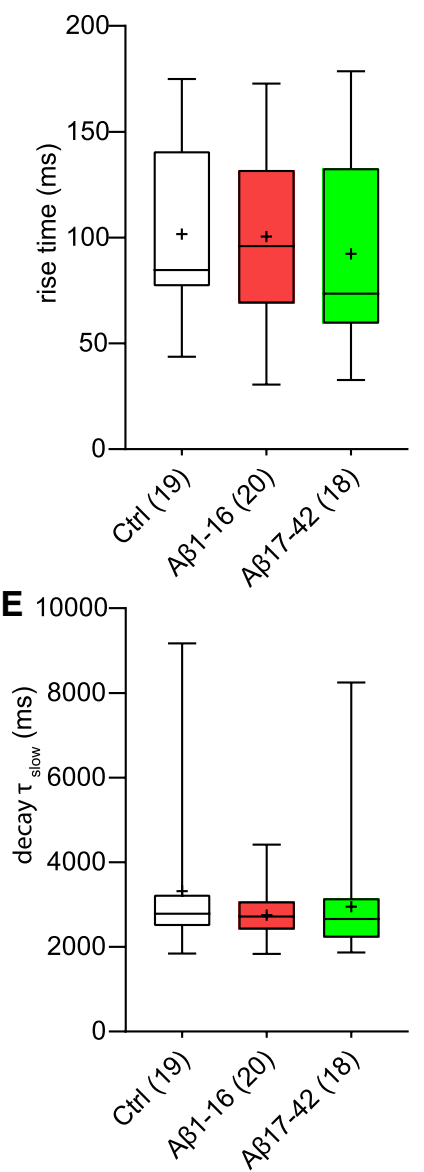

Fig. $5 \mathrm{~A} \beta 1-16$, but not $\mathrm{A} \beta 17-42$, modulates nicotine-induced inward current of $\alpha 7 \mathrm{nAChRs}$. a Representative whole-cell current traces of $\alpha 7 \mathrm{nAChRs}$ transiently expressed in HEK293T cells evoked by $300 \mathrm{~ms}$ puffs of $200 \mathrm{pM}$ human $\mathrm{A} \beta 1-16$ or by $100 \mu \mathrm{M}$ nicotine in the presence of vehicle (Ctrl), $200 \mathrm{pM}$ human A $\beta 1-16$ or human/ rat A $317-42$. Cells were held at $-70 \mathrm{mV}$. Quantification of nicotineevoked peak current amplitude (b) and rise time (c). Time constant $(\tau)$ of the fast (d) and slow (e) component of current decay in

\section{A $\beta$-derived fragments differently affect phosphorylation of synapsin 1 at serine 551}

Our previous data indicated a contribution of cyclindependent kinase 5 (CDK5)/calcineurin balance in the $\mathrm{A} \beta$-dependent regulation of SV recycling downstream of $\alpha 7 n A C h R s$ [28]. CDK5-mediated phosphorylation of Syn1 at serine 551 (pSyn1S551) controls the transition of SVs from recycling to resting pool [45]. Thus, we assessed possible regulation of this phospho-specific site by $\mathrm{A} \beta$ and its fragments. To this end, mature rat cortical neurons were immunostained with an antibody recognizing pSyn1S551 and with a polyclonal anti-Syn1,2 antibody. We found that the number of synaptic puncta positive for pSyn1S551 was unchanged upon treatment with $\mathrm{A} \beta$-derived peptides response to nicotine puff application in all conditions. $\tau$ was estimated by fitting the fast and slow phase of current decay with a bi-exponential function. Values in brackets refer to the number of recorded cells. Boxes indicate the interquartile range with median, whiskers minimum and maximum values, and + shows the mean. One-way ANOVA with Dunnett's multiple comparisons test (c) or Kruskal-Wallis test with Dunn's post hoc test (b, d, e) were used for comparisons to Ctrl; $* * * p<0.001$.

(Fig. 6a,b; $A \beta 1-40: 0.90 \pm 0.05$; $A \beta 1-42: 0.84 \pm 0.06$; $A \beta 1-$ 16: 0.84 \pm 0.06; $A \beta 17-40: 0.80 \pm 0.09, A \beta 17-42: 0.95 \pm 0.06$; Ctrl: $1 \pm 0.03)$. However, the synaptic IF intensities were differentially regulated upon application of peptides. While treatment with the peptides containing the first 16 aa of $A \beta$, namely $A \beta 1-40, A \beta 1-42$ and $A \beta 1-16$, significantly decreased the IF intensity of pSyn1S551 as compared to the untreated control (Fig. 6a,c; A $\beta 1-40: 0.81 \pm 0.04 ; \mathrm{A} \beta 1-42: 0.82 \pm 0.05$; $\mathrm{A} \beta 1$-16: $0.76 \pm 0.04$; Ctrl: $1 \pm 0.04)$, an application of $A \beta 17$ 42 and $A \beta 17-40$ had opposite effect (Fig. 6a,c; $A \beta 17-40$ : $1.21 \pm 0.07, \mathrm{~A} \beta 17-42: 1.20 \pm 0.06$ ).

The phosphatase that antagonises the effect of CDK5 on S551 is calcineurin [21]. Calcineurin activation is calcium dependent and thus, a good candidate to mediate the $\mathrm{Ca}^{2+}$ signalling downstream of $\alpha 7 \mathrm{nAChR}$. To assess 

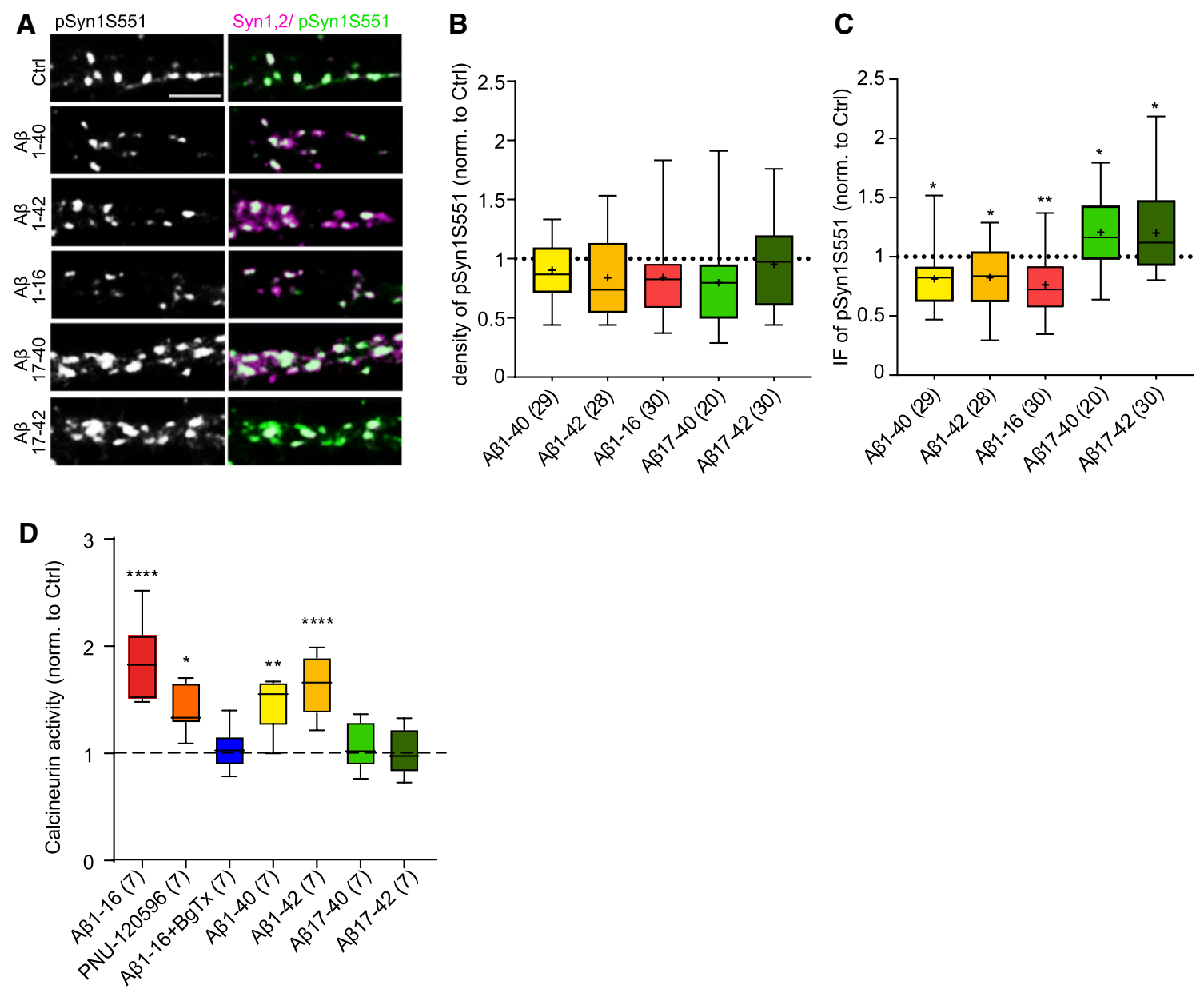

Fig. 6 A $\beta$-derived fragments differently affect phosphorylation of Syn 1 at serine 551 and calcineurin activity. a Representative images of mature cortical neurons (17-22 DIV) treated with vehicle (Ctrl), rat $A \beta 1-40$, rat $A \beta 1-42$, human $A \beta 1-16$, human/rat $A \beta 17-40$, human/ rat $\mathrm{A} \beta 17-42$ for $1 \mathrm{~h}$ at $37{ }^{\circ} \mathrm{C}$ and stained with antibodies recognizing Syn1 phosphorylation at serine 551 (pSyn1S551, green). Syn1,2 (magenta) was used as a synaptic marker. Scale bar $5 \mu \mathrm{m}$. b Quantification of the density and $\mathbf{c}$ IF intensity of synaptic puncta positive for pSyn1S551. (D) Quantification of calcineurin activity in cortical

directly, whether physiological $A \beta$ affects the calcineurin activity, we treated cultured neurons with $A \beta 1-40$ and A $\beta 1-42$ peptides and fragments covering their $\mathrm{N}-$, and C-terminal domain, i.e., $\mathrm{A} \beta 1-16$ and $\mathrm{A} \beta 17-40$ and $\mathrm{A} \beta 17$ 42 , respectively, and measured calcium-dependent phosphatse activity using a selective calcineurin substrate RII and colorimetric detection in lysates form treated cells. The calcineurin activity was significantly increased in cells treated with all fragments contain the N-terminal portion of $A \beta$ including $A \beta 1-16, A \beta 1-40$ and $A \beta 1-42$, while the $C$-terminal fragments $A \beta 17-40$ and $A \beta 17-42$ had not effect (Fig. 6d; $A \beta 1-16: 1.89 \pm 0.14$; $A \beta 1-40: 1.46 \pm 0.10$; $\mathrm{A} \beta 1-42: 1.62 \pm 0.10 ; \mathrm{A} \beta 17-40: 1.05 \pm 0.08$ and $\mathrm{A} \beta 17-42$ : $1.01 \pm 0.08$; all normalised to control). Importantly, a neurons (21DIV) treated with A $\beta$ peptides, BgTx and PNU-120596. Data were normalized to the Ctrl. In plots, the boxes show the interquartile range and median, whiskers minimum and maximum values, and +indicates the mean. Values in brackets are the in $\mathbf{b}$ and $\mathbf{c}$ number of analysed cells obtained from three independent experiments and in $\mathbf{d}$ numbers of independent experiments. One-way ANOVA followed by Dunnett's post hoc test was applied to assess statistical significance of comparison to $\mathrm{Ctrl} ;{ }^{*} p<0.05, * * p<0.01$, **** $p<0.0001$

co-application of BgTx with A $\beta 1-16$ completely abolished the activation of calcineurin (Fig. $6 \mathrm{~d}$; A $\beta 1-16+\mathrm{BgTx}$ : $1.05 \pm 0.08)$. An application of PNU-120596 (3 $\mu \mathrm{M})$, which is well-known positive allosteric modulator type II of $\alpha 7 \mathrm{nAChRs}$, led to increased calcineurin activity further supporting the key role of $\alpha 7 \mathrm{nAChRs}$ in $\mathrm{A} \beta 1-16$-induced calcineurin activation (Fig. 6d; PNU-120596: 1.40 \pm 0.08 ).

Altogether, this data showed a distinct effect of $A \beta$ isoforms on the cellular signalling. Interestingly, the fragments containing the $\mathrm{N}$-terminal part had a distinct effect compared to the peptides covering the $\mathrm{C}$-terminal part. The $16 \mathrm{~N}$-terminal aa were required for calcineurin activation and pSyn 1 S551 dephosphorylation downstream of $\alpha 7$ nAChRs. 


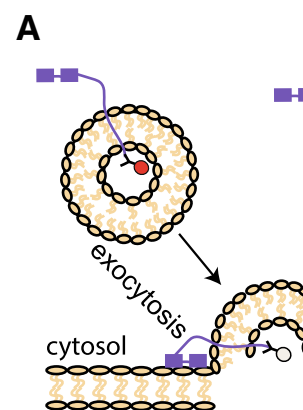

extracellular ${ }^{\infty} \mathrm{pH} 7.4$

B

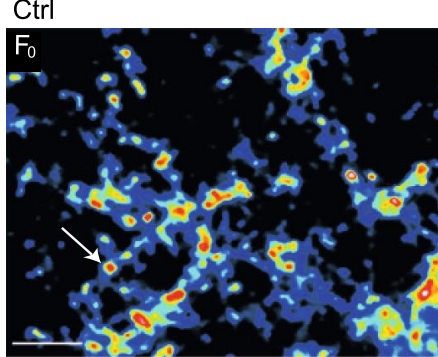

Aß1-16

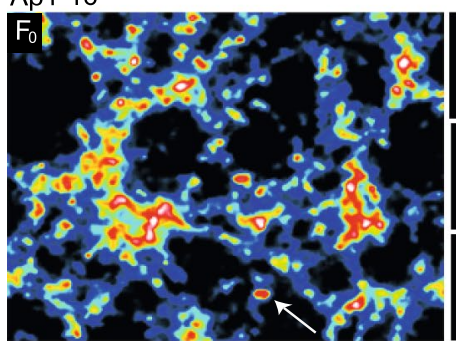

E

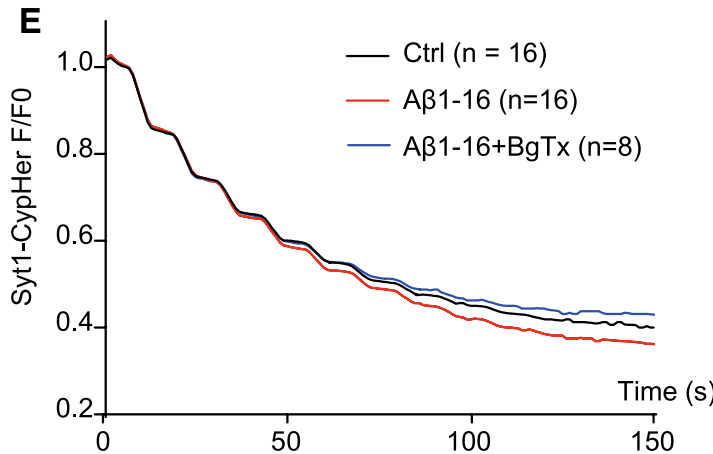

G
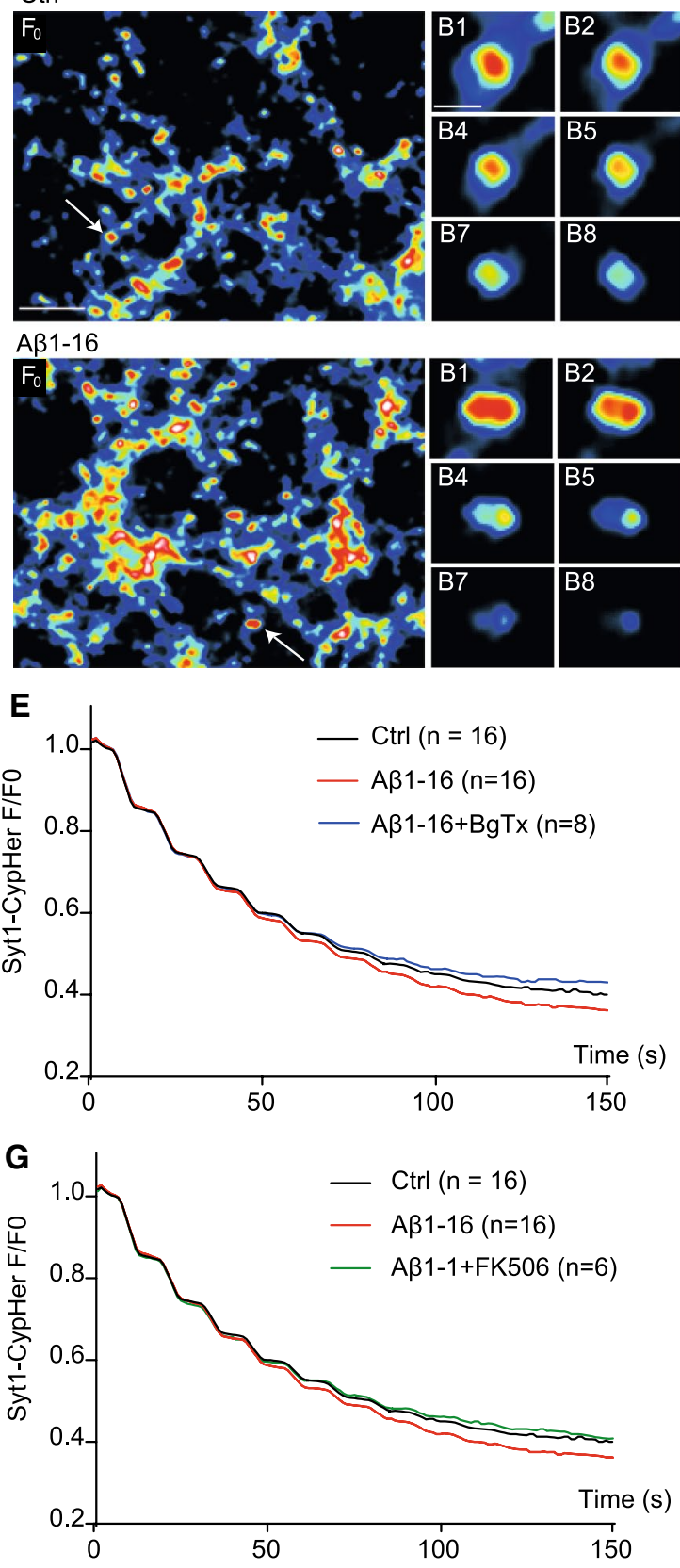

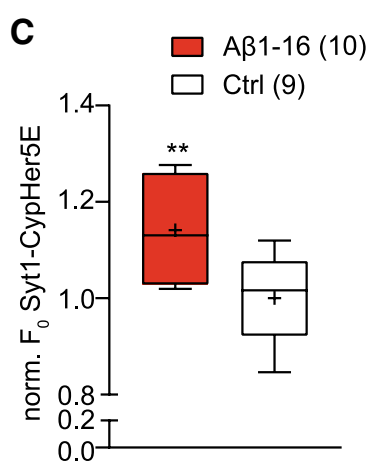

0
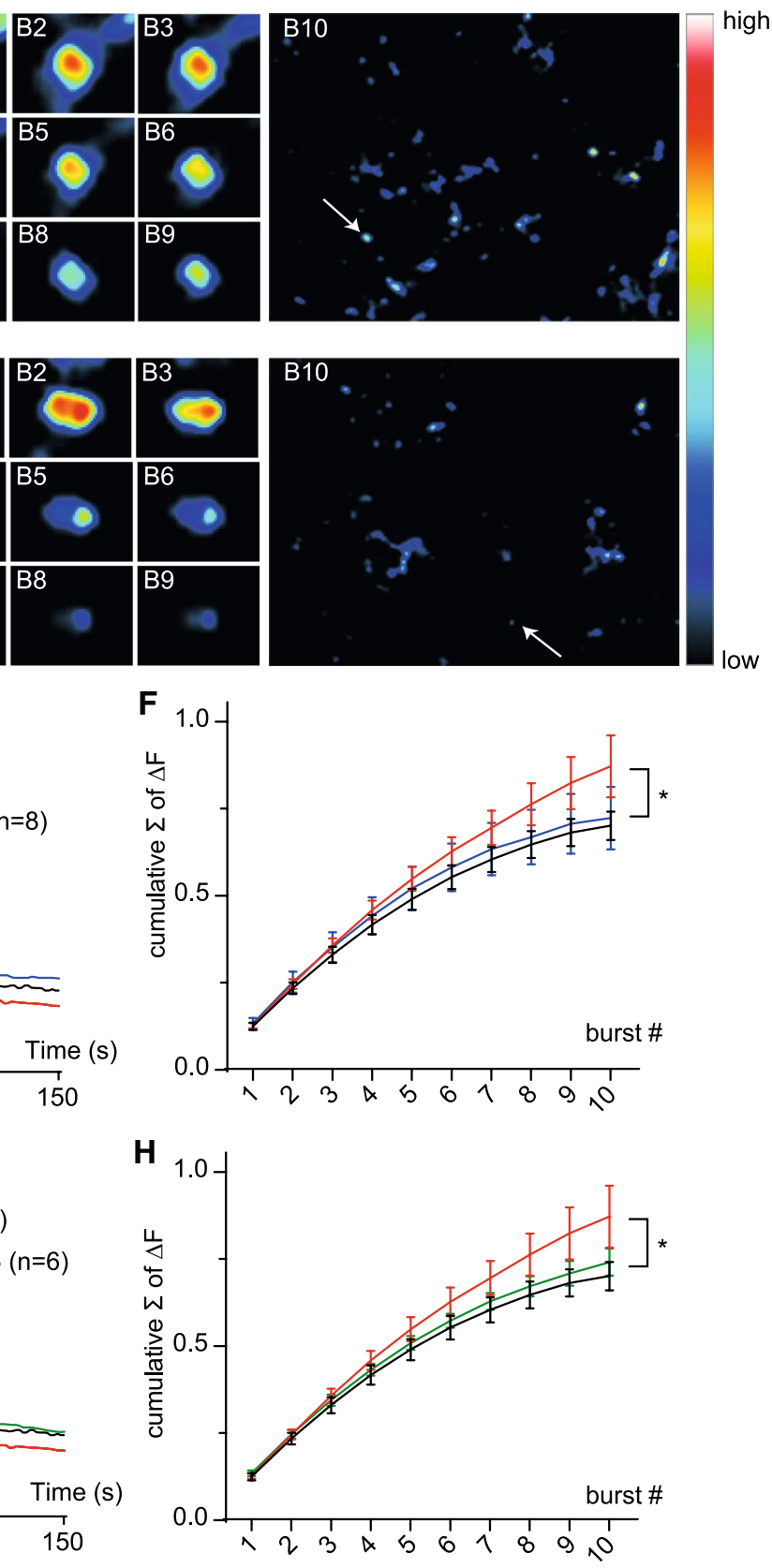
४Fig. 7 The N-terminal A $\beta$ increases availability of SVs during repetitive stimulation dependently on $\alpha 7 \mathrm{nAChR}$ and calcineurin activation. a Schematic representation of the Syt1-CypHer5E imaging. At rest, the fluorescence (F) of CypHer5E is completely unquenched in the low intra-vesicular $\mathrm{pH}(\sim 5.5)$ and gets quenched upon SV exocytosis in the neutral extracellular media $(\sim 7.4)$. Following endocytosis and vesicular reacidification, the CypHer5E $\mathrm{F}$ increases again. Blockade of the v-ATPase with bafilomycin A1 prevents vesicular reacidification trapping $\mathrm{SV}$ s in the alkaline state. b Representative image $\mathrm{F}_{0}$ shows typical Syt1-CypHer5E loading in hippocampal neurons (17-20 DIV) incubated with either vehicle (Ctrl) or human A $\beta 1-16(200 \mathrm{pM})$ for $1 \mathrm{~h}$ at $37{ }^{\circ} \mathrm{C}$ in Tyrode's buffer with choline before Syt1-CypHer5E loading $\left(1 \mathrm{~h}, 37^{\circ} \mathrm{C}\right)$. c Quantification of the Syt1-CypHer5E loading $\left(F_{0}\right)$. Images B1-B9 show the course of destaining of an individual synapse (marked by arrow in the $\mathrm{F}_{0}$ overview image) upon application of stimulation protocol shown in $\mathbf{d}$ in the presence of bafilomycin A $(1 \mu \mathrm{M})$. B10 shows the whole region upon application of the final stimulus. Scale bar is $5 \mu \mathrm{m}$ in overview and $1 \mu \mathrm{m}$ in close-up image. d Schematic representation of applied stimulation protocol. After $10 \mathrm{~s}$ of baseline, 10 bursts (B1-B10) of $40 \mathrm{AP}$ at $20 \mathrm{~Hz}$ spaced by $10 \mathrm{~s}$ pause were applied via electrical field stimulations. Imaging was continued for additional $60 \mathrm{~s}$. e,g Traces showing average time-course of Syt1-CypHer5E F in response to the stimulation protocol in control and cells treated with A $\beta 1-16$ alone or in presence of either BgTx (E) or FK506 (G). All values were normalized to $F_{0} \mathbf{f}, \mathbf{h}$ Cumulative amplitude of Syt1-CypHer5E F calculated from curves shown in e and $\mathbf{g}$. Data are obtained from at least four independent experiments and are expressed as a mean $(\mathbf{e}, \mathbf{g})$ or mean \pm SEM $(\mathbf{f}, \mathbf{h})$ or as boxes depicting the interquartile range and median, with whiskers showing minimum and maximum values, and mean showed as $+(\mathbf{c})$. Values in brackets show the number of analysed coverslips from four independent experiments. Unpaired $t$ test was used to estimate statistical significance; $* p<0.05, * * p<0.01$

\section{A $\beta$ 1-16 increases size of recycling pool to sustain NT release}

To directly address, whether the increased TRP revealed in $\mathrm{A} \beta$-treated neurons by a chemical depolarizing stimulus (4 min, $52.5 \mathrm{mM} \mathrm{KCl}$ ) contributes to the $\mathrm{SV}$ release evoked by electrical activity, we decided to perform live imaging experiments. To this end, we labelled recycling SVs in neurons using Syt $1 \mathrm{Ab}$ coupled with a $\mathrm{pH}$-sensitive dye CypHer5E (Syt1-CypHer5E). As depicted in Fig. 7a, this dye exhibits maximal fluorescence in the acidic intravesicular environment of a SV, is quenched upon exocytosis in the neutral $\mathrm{pH}$ of extracellular media and becomes visible again following endocytosis and vesicular re-acidification [19]. The neurons treated with $\mathrm{A} \beta 1-16$ (in $28 \mu \mathrm{M}$ choline-containing TB) for $1 \mathrm{~h}$ before and during Syt1CypHer5E showed significantly higher loading (i.e., fluorescence at baseline, F0) than the control (Fig. 7b, c; A $\beta 1$ 16: $1.14 \pm 0.03$; Ctrl: $1 \pm 0.03$ ) indicating that a higher number of SVs underwent exo-endocytosis during the labelling period. To analyse the recruitment of SV for neurotransmission during repetitive stimulations, we applied ten consecutive bursts (40 AP-inducing pulses at $20 \mathrm{~Hz}$ ) spaced by $10 \mathrm{~s}$ intervals via field electrodes (Fig. 7d). The applied bursts were shown to release the entire readily releasable pool (RRP) in this neuronal preparation [4]. We performed this experiment in the presence of bafilomycin A1 that blocks vesicular reacidification to visualize release of all newly recruited SVs only (Fig. 7A). Under these conditions, the fluorescence reaches a maximum corresponding the release and alkalization of all SVs that are able to undergo exocytosis during the applied stimulation (Fig. 7d). The decline of fluorescence was more pronounced in A $\beta$-treated cells (Fig. 7b images B1-B10 and Fig. 7e). The relative change in the fluorescence was calculated for each burst as $\Delta F x=(F x \max -F x \min ) / F x \max$, where $F_{x \max }$ and $F_{x \min }$ express the maximal and minimal fluorescence detected at burst $x$. The cumulative plot of burst-induced changes in fluorescence indicates that a larger proportion of labelled SVs can be mobilized during repetitive stimulations in cells treated with $A \beta 1-16$ compared to control cells (Fig. 7f). Blockade of $\alpha 7 \mathrm{nAChR}$ with BgTx or application of calcineurin inhibitor FK506 completely abolished effect of A $\beta 1-16$ (Fig. 7e-h). Collectively, these data indicate that A $\beta 1-16$ increases availability of SVs for neurotransmission via promoting their recruitment and mobilization for exocytosis and reveal a role of calcineurin signalling downstream of $\alpha 7 \mathrm{nAChR}$ in this process.

\section{Discussion}

Over the past decade, the view on the role of $A \beta$ in the regulation of neuronal function has dramatically changed. Initially, $A \beta$ was considered as a metabolic garbage product which, if not removed properly, forms neurotoxic amyloid plaques that literally clog the brain causing neurodegeneration and cognitive decline. More recently, multiple studies confirmed a beneficial physiological role of $A \beta$ in the regulation of synaptic plasticity and memory $[11,33$, $38,39]$. A positive regulatory effect of $\mathrm{A} \beta$ in physiological $(\approx 200 \mathrm{pM})$ concentrations on SV recycling has been documented by several previous studies [1, 10, 28]. In the presented study, we set up to investigate the mechanism, by which $A \beta$ exerts this regulation. We dissected the differential effects of $\mathrm{N}$ - and C-terminal fragments of A $\beta 1-40 / 42$. At $\mathrm{pM}$ concentrations, the N-terminal fragment $\mathrm{A} \beta 1-16$, but not the $\mathrm{C}$-terminal $\mathrm{A} \beta 17-40 / 42$, possessed all positive regulatory properties of high mass $\mathrm{A} \beta 1-40 / 42$ peptides. At the level of individual glutamatergic synapses, it increased the availability of SVs for release by their mobilization and recruitment to the recycling pool. This presynaptic effect was driven by enhancement of calcineurin activity downstream of $\alpha 7 \mathrm{nAChRs}$ leading to dephosphorylation of SV-associated protein Syn1 and consequent reorganization of functional SV pools. 


\section{The $\mathrm{N}$-terminal domain (A $\beta 1-16)$ mediates the presynaptic effect of $A \beta 1-42$}

In this study, we demonstrate differential effects of $\mathrm{N}$ - and C-terminal fragments of A $\beta 1-42$ on regulation of SV recycling. Whereas A $\beta 1-16$, similarly as we have shown previously for A $\beta 1-42$ [28], increased the size of TRP of SVs, the C-terminal fragment $A \beta 17-42$ had no effect. It has been well established that physiological (pM) A $\beta 1-42$ acts as an important endogenous regulator of neurotransmission. Its effects on neuroplasticity were demonstrated in several experimental settings including animal behavioural, electrophysiological recordings of hippocampal LTP as well as optical and electrophysiological studies of synaptic potentiation in cultured neurons and hippocampal slices [1, 14, $28,38,39]$. Two recent studies indicate the importance of the N-terminal fragment of A $\beta 1-42$ in this process. Richter and colleagues demonstrated that expression of APPs $\alpha$, but not the APPs $\beta$, increased synaptic plasticity and rescued memory defects in conditional APP/APLP2 KO mice (2018). APPs $\alpha$ and APPs $\beta$ are the soluble ectodomains of APP that arise upon its cleavage with $\alpha$ - and $\beta$-secretases, respectively, and differ only in the 16 aa sequence covering the $A \beta 1-16$ peptide. A direct application of $A \beta 1-15$ or $A \beta 1-$ 16 was also able to increase hippocampal LTP in vitro and memory formation in vivo, confirming that the N-terminal domain of A $\beta 1-42$ mediates these neuroplasticity effects [27, 40]. Thus, we propose that the well-documented positive effect of $A \beta 1-42$ on synaptic plasticity and memory resides in its N-terminal domain and most likely relies on the effect of A $\beta 1-16$ on SV recycling. The N-terminal fragments of $A \beta$ ending around the aa 16 are among the most abundant $\mathrm{A} \beta$ isoforms found in human CSF [35, 37]. The generation of these $\mathrm{N}$-terminal $\mathrm{A} \beta$ isoforms depends on concerted action of $\alpha$ - and $\beta$-secretases, but does not involve the $\gamma$-secretase [36]. This opens a possibility that activation of a specific APP processing pathway leads to specific regulations of neurotransmission.

\section{a7nAChRs is the molecular target transducing effects of physiological $A \beta 1-16$}

A growing body of evidence supports the role of $\alpha 7 \mathrm{nAChRs}$ in the physiological effect of A $\beta 1-42$ on neurotransmission and neuroplasticity. Probably most convincing are the experiments showing that the enhancement of LTP and memory induced by application of pM A $\beta 1-42$ were completely blocked by a selective antagonist of $\alpha 7 \mathrm{nAChRs} \mathrm{BgTx}$ and absent in $\alpha 7 \mathrm{nAChRs}$ KO mice [39]. Our previous study proposed a crucial role for $\alpha 7 \mathrm{nAChRs}$ in the A $\beta 1-42$-dependent bidirectional hormetic regulation of $\mathrm{SV}$ recycling in cortical neurons [28]. Here, we confirmed and extended these findings. A pharmacological blockade of $\alpha 7 \mathrm{nAChRs}$ with
BgTx or their genetic removal (CHRNA7 KO) completely prevented the increase of TRP of SV at glutamatergic synapses upon application of $\mathrm{A} \beta 1-16$ or $\mathrm{A} \beta 1-42$.

While a direct binding of $\mathrm{A} \beta 1-42$ to $\alpha 7 \mathrm{nAChRs}$ has been indicated by multiple studies $[6,47,48]$, the mode of regulation of $\alpha 7 \mathrm{nAChRs}$ by $\mathrm{A} \beta$ is a subject of an ongoing debate. While few studies suggest that $A \beta$ acts in a concentration-dependent manner as a direct agonist or antagonist of $\alpha 7 \mathrm{nAChRs}[26,34]$ our data could not confirm this view. In our hands, $A \beta 1-16$ required physiological concentrations of choline to increase SV recycling in neurons. Moreover, $A \beta 1-16$ and $A \beta 1-42$ failed to induce signalling through $\alpha 7 \mathrm{nAChRs}$ if applied alone, but significantly potentiated nicotine-induced $\mathrm{Ca}^{2+}$ influx and inward currents as assessed by $\mathrm{Ca}^{2+}$ imaging and whole-cell patch-clamp recordings in HEK293T cells. Thus, we suggest that physiological A $\beta 1-16$ has a modulatory effect on agonist-induced signalling via $\alpha 7$ nAChRs. An enhancement of agonist-evoked peak current amplitude of $\alpha 7 \mathrm{nAChRs}$ without changing their gating kinetics indicates that $\mathrm{A} \beta 1-16$ acts as a type I positive allosteric modulator of $\alpha 7 \mathrm{nAChRs}$ [12]. This is in line with a previous study showing a significant leftward shift in the nicotine dose-response curve of $\alpha 7 \mathrm{nAChRs}$ upon application of sAPP $\alpha$, but not of sAPP $\beta$ differing only in the A $\beta 1$ 16 sequence on their C-terminus [40]. Finally, direct measurement of calcineurin activity in primary neurons revealed that $\mathrm{A} \beta$ fragments containing the $16 \mathrm{~N}$-terminal aa elevated activity of this phosphatase. This effect was dependent on activity of $\alpha 7 \mathrm{nAChRs}$; it was completely blocked by $\alpha 7 \mathrm{nAChR}$ antagonist BTX. In line with this, an application of positive allosteric modulator PNU-120596 had similar affect as $\mathrm{A} \beta 1-16$.

Thus, considering the crucial role of $\mathrm{Ca}^{2+}$ signalling in the positive effect of $A \beta$ on SV recycling shown previously [28] and in this study, we propose that A $\beta$ controls SV recycling at glutamatergic synapses by modulation of calcineurin activity downstream of cholinergic activation of presynaptic $\alpha 7$ nAChRs.

\section{$A \beta 1-16$ increases TRP via changes in the phosphorylation of SV-associated protein synapsin}

Previous work linked the increase of SV recycling upon modulation of physiological $A \beta$ to a dynamic regulation of CDK5/calcineurin balance [28]. CDK5 is well established to decrease size of recycling pool by stabilizing SVs in the resting pool, an effect that is counterbalanced by the $\mathrm{Ca}^{2+}$-dependent phosphatase calcineurin [24, 31]. The phosphorylation of serine 551 of Syn 1 (pSyn1S551) is dynamically regulated by CDK5 and calcineurin upon $\mathrm{Ca}^{2+}$ entry [21]. Verstegen and collaborators showed that the phosphorylation of Syn1 at serine 551 (pSyn1S551) is the molecular 
target underlying CDK5 effects, since it favours the binding of SV-associated protein Syn1 and actin filaments promoting clustering of SVs into the resting pool (2014). In this work, we extended our previous finding and showed that application of $200 \mathrm{pM}$ A $\beta$ fragments that contain $16 \mathrm{~N}$-terminal aa increased activity of calcineurin downstream of $\alpha 7 \mathrm{nAChRs}$. Moreover, our data revealed consistent downregulation of pSyn1S551 phosphorylation upon treatment with physiological $(200 \mathrm{pM}) \mathrm{A} \beta$ peptides containing the $\mathrm{N}$-terminal sequence (A $\beta 1-16, A \beta 1-40, A \beta 1-42)$, which is in line with the observed increase in TRP likely due to a shift of SVs from the resting into recycling pool. Interestingly, the $A \beta$ fragments containing the C-terminal sequence (A $\beta 17-40$, $A \beta 17-42$ ) increased the pSyn1S551. This might be due to an interference with endogenous A $\beta$ signalling. Finally, the increased SV mobilisation observed upon repetitive stimulation in neurons pre-treated with $A \beta 1-16$ was blocked by co-application of $\alpha 7 \mathrm{nAChR}$ antagonist BgTx or by pharmacological inhibition of calcineurin activity further supporting the significance of calcineurin activation downstream of $\alpha 7 \mathrm{nAChRs}$ in the regulation of SV recycling by physiological A $\beta 1-16$.

Altogether, our data demonstrate an important role for the $\mathrm{N}$-terminal $\mathrm{A} \beta$ fragment as a potent enhancer of cholinergic signalling via $\alpha 7 \mathrm{nAChRs}$. The $\mathrm{Ca}^{2+}$ influx through these receptors, activation of phosphatase calcineurin and subsequent change in phosphorylation of Syn1 induces mobilisation of SVs from the resting to the recycling pool, which supports sustained NT release. In AD, high A $\beta$ levels were reported in early stages followed by decreased free extracellular $A \beta$ levels. Both, low or excessive production of the $\mathrm{N}$-terminal $\mathrm{A} \beta$ fragment will decrease the dynamic range of signalling via $\alpha 7 \mathrm{nAChRs}$ and thus, lead to deficits in cholinergic modulation. Cholinergic dysfunction is well established in AD. The current pharmacological treatments that, at least intermediately, ameliorate the cognitive decline target cholinergic signalling [17]. Our findings provide a plausible mechanistic explanation for this fact. Moreover, they support the emerging role of physiologically occurring $\mathrm{A} \beta$ fragments in cholinergic modulation of glutamatergic neurotransmission.

\section{Materials and methods}

\section{Animals}

Primary rat neuronal cultures used in this study were prepared from E18 embryos of a pregnant Sprague-Dawley rat (RjHan:SD, Janvier Labs, Le Genest Saint-Isle, France), while primary mouse neuronal cultures from new-born homozygous Chrna $7^{\text {flox/flox }}$ mice obtained from Jackson laboratories (B6 (Cg)-Chrna7 ${ }^{\mathrm{tm} 1.1 \mathrm{Eh}}$, \#026965,
Jackson Laboratory, Bar Harbor, Maine, USA) and bred on C57BL/6 J background. All experiments were performed following the European Directive 2010763/EU and according to the local announcement and reporting regulations.

\section{Antibodies}

For immunocytochemistry and live staining, the following antibodies were used: rabbit primary antibodies against synaptotagmin 1 for uptake in mouse cells (Oyster550labelled, 1:100, \#105103C3, Synaptic Systems, Göttingen, Germany), synapsin 1,2 (1:1000, \#106002, Synaptic Systems), phospho-synapsin 1 (pSyn1S553) (human pS553 corresponds to pS551 in rat; 1:1000, \#ab32532, Abcam, Cambridge, UK), VGLUT1 (rat cultures, 1:1000, \#135303, Synaptic Systems), VGAT (1:1000, \#131003, Synaptic Systems). Antibodies against synapsin 1,2 (1:1000, \#106004, Synaptic Systems) were raised in guinea pig. Antibodies against synaptotagmin 1 for monitoring SV recycling in rat neuronal cells (Oyster550-labelled, 1:250, \#105311C3, Synaptic Systems and CypHer5E-labelled, 1:200, \#105311CpH, Synaptic Systems), against MAP2 (1:1000, \#M4403, SigmaAldrich, St. Louis, Missouri, USA) and against VGLUT1 (mouse cultures, 1:250 \#135311, Synaptic Systems) were raised in mice. Fluorescent secondary antibodies anti-rabbit Alexa 488 (1:1000, \#711545152), anti-guinea pig Alexa 488 (1:1000, \#706545148), anti-guinea pig Cy3 (1:1000, \#706165148), anti-rabbit Cy3 (1:1000 for rat and 1:500 for mouse cultures \#711,165,152) and anti-mouse Cy5 $(1: 1000$ \#715175150) were all raised in donkey and purchased from Jackson ImmunoResearch Laboratories (West Grove, Pennsylvania, USA).

\section{Chemical reagents}

Choline chloride (\#C7527), nicotine (\#N0267) and FK-506 monohydrate (\#F4679) were purchased from Sigma-Aldrich. $\alpha$-Bungarotoxin (BgTx, \#11032794) and Bafilomycin A1 (\#88899552) from Calbiochem (San Diego, California, USA) and Bicuculline methiodide (Bicu, \#120108) from Abcam. D-(-)-2-Amino-5-phosphonopentanoic acid (APV, \#0106), 6-Cyano-7-nitroquinoxaline-2,3-dione disodium (CNQX, \#0190), Tetrodotoxin (TTX, \#1078), PNU120596 (\#2498) and rat A $\beta 1-40$ (\#2424, DAEFGHDSGFEVRHQKLVFFAEDVGSNKGAIIGLMVGGVV), rat A $\beta 1-42$ (\#2425, DAEFGHDSGFEVRHQKLVFFAEDVGSNKGAIIGLMVGGVVIA) and human A $\beta 1-42$ (\#1428, DAEFRHDSGYEVHHQKLVFFAEDVGSNKGAIIGLMVGGVVIA) peptides, were obtained from Tocris Bioscience (Bristol, UK). Human A $\beta 1-16$ (\#SPBA16, DAEFRHDSGYEVHHQK), human/rat A $\beta 17-40$ (\#SP5043; LVFFAEDVGSNKGAIIGLMVGGVV) and human/rat A 17-42 (\#SP5044; LVFFAEDVGSNKGAIIGLMVGGVVIA) peptides were 
purchased from Innovagen (Lund, Sweden). Human A $\beta 1$ 42 was used for $\mathrm{Ca}^{2+}$ imaging and rat $\mathrm{A} \beta 1-42$ for all other experiments. Pilot experiments (data not shown) confirmed that peptides containing the human and rodent $\mathrm{N}$-terminal sequence have indistinguishable effects on SV recycling. All peptides were dissolved in $\mathrm{H}_{2} \mathrm{O}$ according to the manufacturer's instructions and stored in small aliquots at $-80{ }^{\circ} \mathrm{C}$. For each experiment, fresh aliquots of peptides were used. $\mathrm{H}_{2} \mathrm{O}$ was used as vehicle treatment.

\section{Primary rat neuronal cultures}

Primary rat neuronal cultures were prepared as previously described [29]. Pregnant mice were deeply anesthetized with isoflurane (CP-Pharma, Burgdorf, Germany) and sacrificed by decapitation, the E18 embryos were removed by a cesarean section. The brains were collected on ice-cold HBSS-/- (\#14175053, Thermo Fisher Scientific, Waltham, Massachusetts, USA) freed from skull and meninges and dissected into cortex and hippocampal regions under microscope (Stemi DV4, Zeiss, Oberkochen, Germany). After treatment with $0.25 \%$ (v:v) of Trypsin (\#15400054, Thermo Fisher Scientific) for 20 min at $37{ }^{\circ} \mathrm{C}$ followed by mechanical trituration in presence of $0.1 \mathrm{mg} / \mathrm{ml}$ DNase I (\#11284932001, Roche, Basel, Switzerland), cell suspension was filtered through nylons filters $(100 \mu \mathrm{m})$ and then plated at the required density in DMEM (\#41966029, Thermo Fisher Scientific) containing 10\% (v:v) fetal calf serum (FCS, \#S0015, Biochrom GmbH, Berlin, Germany), $2 \mathrm{mM}$ L-Glutamine (\#25030024) and 1\% (v:v) Antibiotic/ Antimycotic (\#15240062) (both Thermo Fisher Scientific). $1 \mathrm{ml}$ cell suspension with a density of 25,000 cells $/ \mathrm{ml}$ for electrophysiology, 100,000 cells/ml for immunocytochemistry (ICC) and 120,000 cells/ml for live-imaging experiments was plated on poly-L-lysine (PLL, \#P1524, Sigma-Aldrich) coated $18 \mathrm{~mm}$ Menzel glass coverslips (\#6311342, VWR International, Radnor, USA). For calcineurin activity measurements, 500.000 cells were plated per 1 well in 6-well plate. One hour after plating, the medium was replaced by Neurobasal medium (\#12348017) supplemented with 2\% (v:v) B27 (\#17504044), 0.8 mM L-Glutamine and 1\% (v:v) Antibiotic/Antimycotic (all from Thermo Fisher Scientific).

\section{Immunocytochemistry, synaptotagmin 1 antibody uptake assay and image analysis}

ICC and Syt $1 \mathrm{Ab}$ uptake assay were performed according to an established protocol [29]. For ICC, cortical neurons were fixed in 4\% (w:v) paraformaldehyde (PFA) containing 4\% (w:v) glucose in PBS for 3 min at room temperature (RT, $\left.22 \pm 1{ }^{\circ} \mathrm{C}\right)$, blocked in PBS containing $10 \%(\mathrm{~V}: \mathrm{V})$ FCS and $0.1 \%$ (w:v) glycine and next permeabilized with $0.3 \%$ (v:v) TritonX 100 in PBS for 40 min. Cells were incubated with primary antibodies overnight at $4{ }^{\circ} \mathrm{C}$ and after three PBS washing steps, with secondary antibodies for $1 \mathrm{~h}$ at RT. All antibodies were diluted in PBS containing 3\% (v:v) FCS. Following incubation, coverslips were washed again three times with PBS and mounted on slides using Mowiol 4-88 (\#0713, Carl Roth, Karlsruhe, Germany) or Fluoroshield mounting media without or with DAPI (\#F6182 or \#F6057, Sigma-Aldrich). For the TRP labelling, the fluorescently labelled antibody against the lumenal domain of Syt 1 was applied to the cells in a high $\mathrm{KCl}$-containing Tyrode's Buffer (TB, in $\mathrm{mM}: 69 \mathrm{NaCl}$ and $52.5 \mathrm{KCl}, 2 \mathrm{CaCl}_{2}, 2 \mathrm{MgCl}_{2}, 30$ glucose, 25 HEPES, pH 7.4) at RT for 4 min. Coverslips were washed three times with physiological TB (in mM: 119 $\mathrm{NaCl}, 2.5 \mathrm{KCl}, 2 \mathrm{CaCl}_{2}, 2 \mathrm{MgCl}_{2}, 30$ glucose, 25 HEPES, $\mathrm{pH}$ 7.4) to remove unbound antibody, fixed, blocked and permeabilized as described before. For each experiment, two coverslips per condition were treated simultaneously with the same reagents and antibodies. All mounted samples were kept at $4{ }^{\circ} \mathrm{C}$ until the day of examination. For mouse neuronal cultures, the IF of Syt1 Ab uptake was amplified using an anti-rabbit Cy3-secondary antibody (1:500). 16-bit images were acquired with a 60X/NA1.2 objective (Plan APO VC Nikon CFI, Nikon Corporation, Tokyo, Japan) using an epi-fluorescence microscope (Nikon Eclipse Ti, Nikon Corporation) equipped with an iXon EM + 885 EMCCD Andor camera (Andor Technology, Belfast, UK) controlled by NIS Elements software (Nikon Corporation) or VisiView software (Visitron System GmbH, Puchheim, Germany). After background subtraction, a $16-\mu \mathrm{m}$-long region of a proximal dendrite localized $8 \mu \mathrm{m}$ away from the soma, was semi-automatically selected and cropped in ImageJ (National Institutes of Health, Bethesda, Maryland, USA). Next, synaptic puncta were semi-automatically identified and colocalized with presynaptic markers VGLUT1, VGAT or Syn1,2. Synaptic puncta mean IF intensities were quantified using Open View software kindly provided by N. Ziv [44].

\section{Production of lentiviral vectors}

The active and inactive nuc-EGFP-cre recombinase (CRE and $\triangle \mathrm{CRE}$ ) were kindly provided by P. Kaeser [22]. Lentiviral vectors were produced in HEK293T cells (ATCC, Manassas, Virginia, USA) as described before [9]. Briefly, cells were transfected with the FUGW-based transfer, psPAX2 packaging and pVSVG pseudotyping vectors [30], in a 2:1:1 molar ratio. After 6-8 h, the existing DMEM supplemented with $10 \%$ (v:v) FCS, 2 mM L-Glutamine, 1\% (v:v) Antibiotic/Antimycotic was replaced by Neurobasal A medium (\#12349015, Thermo Fisher Scientific) supplemented with 1\% (v:v) GlutaMAX TM (\#35050061, Thermo Fisher Scientific), $1 \mathrm{mM}$ sodium pyruvate (\#11360070, Thermo Fisher Scientific), $1 \%$ (v:v) Antibiotic/Antimycotic and 2\% (v:v) 
B27. $48 \mathrm{~h}$ post-transfection, the cell supernatant containing lentiviral vectors was collected and centrifuged at $570 \mathrm{~g}$ for $10 \mathrm{~min}$. The supernatant containing lentiviruses was stored at $-80{ }^{\circ} \mathrm{C}$ in small aliquots to prevent freeze-thaw cycles.

\section{Primary Chrna $7^{\text {flox/flox }}$ mice cultures}

Primary mouse neuronal cultures were prepared according to an established protocol [8] with some modifications.

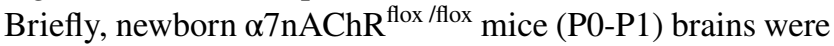
collected and freed of meninges. Brains were mechanically dissociated by pipetting in a dissociation solution containing $0.127 \mathrm{U} / \mathrm{ml}$ of papain (\#LK003176, Worthington Biochemical Corporation, Lakewood, New Jersey, USA), $1 \mathrm{mg}$ / $\mathrm{ml}$ dispase II (\#04942078001, Roche), $0.1 \mathrm{mg} / \mathrm{ml}$ DNase I (\#LS002139, Worthington), $12.4 \mathrm{mM} \mathrm{MgSO}_{4}$ in HBSS-/-, for $10 \mathrm{~min}$ at $37^{\circ} \mathrm{C}$, followed by centrifugation for $5 \mathrm{~min}$ at $120 \mathrm{~g}$. Cell suspension was filtered through nylon cell strainers $(70 \mu \mathrm{m})$, resuspended in Neurobasal A-mix media (Neurobasal A supplemented with $1 \%$ (v:v) GlutaMAX ${ }^{\mathrm{TM}}, 1 \mathrm{mM}$ sodium pyruvate, $1 \%$ (v:v) Antibiotic/Antimycotic and 2\% (v:v) B27), following two additional cycles of mechanical dissociation and centrifugation. Prior to culture preparation, $100 \mu \mathrm{l}$ of Neurobasal A-mix media with $10 \%$ (v:v) FCS was applied on the $18 \mathrm{~mm}$-PLL-coated coverslips, and kept at $37^{\circ} \mathrm{C}$ till plating. 200,000 cells (in a volume of $100 \mu \mathrm{l}$ ) were plated per coverslip and $1 \mathrm{ml}$ of fresh Neurobasal A-mix media was added $1 \mathrm{~h}$ later. All cells were maintained at $37{ }^{\circ} \mathrm{C}$ in a humidified incubator containing $5 \% \mathrm{CO}_{2}$. Cells were transduced with CRE or $\triangle \mathrm{CRE}$ encoding lentivirus at 4 days in vitro (DIV).

\section{qPCR to assess the cre-mediated Chrna7 deletion in Chrna $7^{\text {flox/flox }}$ mice cultures}

Total RNA was extracted from cultures 14 days after viral transduction using Pure Link RNA mini kit (\#12183018A, Life technologies, Carlsbad, California, USA), according to the manufacturer's instructions. The cDNA was synthetized according to SuperScript VILO cDNA Synthesis kit (\#11754050, Invitrogen). qPCR was performed using SYBR-green (\#04707516001, Roche) and a Light cycler 480 II (Roche). Primers were designed to amplify the sequence spanning Chrna7 exon 3-5 (primer pair 1 (PP1): For: 5'TGAGAAGAACCAAGTTTTAACCACC-3'; rev: 5'-ACC AAGACGTTGGTGTGGAA-3') and exon 4-5 sequence (primer pair 2 (PP2): for: 5'- TTCGTTTTCCAGATGGCC AGA-3'; rev: 5'-ACCAAGACGTTGGTGTGGAA-3'). Glyceraldehyde-3-phosphate dehydrogenase (GAPDH) was used as internal control: (for: 5'-CGACTTCAACAGCAA CTCCCACTCTTCC-3'; rev: 5'-TGGGTGGTCCAGGGT TTCTTACTCCTT-3'). The expression level of Chrna7 was normalized to GAPDH and analysed using the delta-delta
Ct method using Light Cycler 480 software (version 1.5, Roche). The size of the qPCR products obtained with PP1 was assessed by agarose gel electrophoresis and the optical density was quantified in image studio software (LI-COR Bioscience, Lincoln, Nebraska, USA).

\section{Culture and transfection of HEK293T cells}

HEK293T (ATCC) cells were cultured in DMEM supplemented with $10 \%$ (v:v) FCS, 2 mM L-Glutamine and $1 \%$ (v:v) of Antibiotic/Antimycotic. At 70\% confluence, cells in T25 flask were transfected using jetPEI kit (\#101, Polyplus transfection, Illkirch, France) according to manufacturer's instructions. For $\mathrm{Ca}^{2+}$ imaging, HEK293T cells in a T25 flask were co-transfected with $2 \mu \mathrm{g}$ of each pcDNA3.1CHRNA7, (\#62276, Addgene, Watertown, Massachusetts, USA, [49]), pCMV6-XL5-TMEM35A (\#SC112910, OriGene Technologies, Rockville, Maryland, USA) together with $75 \mathrm{ng}$ of pCVM-mCherry-N1 (\#632523, Clontech, Mountain View, California, USA) plasmids. For electrophysiological studies, $1 \mu \mathrm{g}$ of each pcDNA3.1-CHRNA7, pCMV6-XL5-TMEM35A and 75 ng pEGFP-C2 (\#6083-1, Clontech, Mountain View, California,USA) were transfected. $48 \mathrm{~h}$ post-transfection, cells were plated either on 96-well PLL-coated clear-bottom black well plates (\#3603, Corning, New York, USA) at a density of 140,000 cells/well and used for $\mathrm{Ca}^{2+}$ imaging experiments on the next day or in $35 \mathrm{~mm}$ TC-treated cell culture dishes (\#353001, Corning) for electrophysiology, and recorded on the same day.

\section{Calcium imaging}

Transfected HEK293T cells were loaded with $4 \mu \mathrm{M}$ of Cal$520 \AA$ AM (\#21130, AAT Bioquest, Sunnyvale, California, USA) at $37^{\circ} \mathrm{C}$ for $75 \mathrm{~min}$ in $\mathrm{Ca}^{2+}$ assay buffer (in mM: 137 $\mathrm{NaCl}, 4 \mathrm{KCl}, 2 \mathrm{CaCl}_{2}, 1 \mathrm{MgCl}_{2}, 5$ glucose, 10 HEPES, 2 probenecid (\#P8761, Sigma-Aldrich), pH 7.4) supplemented with $0.2 \mathrm{mg} / \mathrm{ml}$ Pluronic ${ }^{\circledR}$ F-127 (\#20050, AAT Bioquest). The background fluorescence was determined from unloaded cells. The intracellular $\mathrm{Ca}^{2+}$ influx was recorded using the well mode and the direct optic bottom reading (ex: 483-14 em: 530-30) setting on the CLARIOstar microplate reader (BMG Labtech, Ortenberg, Germany). After $3 \mathrm{~s}$ of baseline, A $\beta 1-16, A \beta 1-42, A \beta 17-42$ or vehicle solution were applied using one on-board reagent injector to achieve final concentration of $200 \mathrm{pM}$. After 2 min of recordings, nicotine was applied using the second on-board reagent injector to final concentration $100 \mu \mathrm{M}$ and the measurements were taken for other 2 min every $0.5 \mathrm{~s}$.

For analysis, the averaged background fluorescence measured in unloaded cells was subtracted from each data point. The average of the baseline before stimulation $\left(F_{0}\right)$ was subtracted from each raw fluorescence intensity $(F)$ and all 
data were normalized to $\mathrm{F}_{0}$, according to the formula: ( $F$ $\left.-F_{0}\right) / F_{0}$

\section{Whole-cell patch clamp}

Transfected HEK293T cells were identified with a 40X objective using an inverted microscope (Axiovert 40, Zeiss) equipped with a fiber-optic-coupled light source (UVICO, Rapp OptoElectronic, Hamburg, Germany). Cells were immersed in extracellular solution containing in $\mathrm{mM}$ : (142 $\mathrm{NaCl}, 4 \mathrm{KCl}, 2 \mathrm{Mg}_{2} \mathrm{Cl}_{2}, 2 \mathrm{CaCl}_{2}, 10$ HEPES, 10 glucose, $\mathrm{pH}$ 7.4, $330 \mathrm{mosm} / \mathrm{l}$ ) and $3 \mathrm{~min}$ after whole-cell access was established, $\alpha 7 \mathrm{nAChRs}$ currents were recorded at RT $\left(22 \pm 1^{\circ} \mathrm{C}\right)$ in whole-cell voltage-clamp mode using an Axopatch 700B amplifier in conjunction with a Digidata 1322A interface controlled by pClamp 10 software (all from Molecular Devices, San Jose, California, USA). Membrane potential was held at $-70 \mathrm{mV}$. Borosilicate glass pipettes with filament (BioMedical Instruments, Zöllnitz, Germany) were pulled with a DMZ-Universal puller (Zeitz-Instruments, Planegg, Martinsried, Germany) and filled with internal solution (containing in mM: $135 \mathrm{~K}$-gluconate, 5 HEPES, 4 $\mathrm{NaCl}, 3 \mathrm{MgCl}_{2}$, 5 EGTA, $2 \mathrm{Na}_{2}$-ATP, $0.3 \mathrm{Na}_{3}$-GTP, pH 7.25, $280 \mathrm{mosm} / \mathrm{l})$. Pipette resistance measured in bath solution was $<5 \mathrm{M} \Omega$ before series resistance compensation (75\%). Nicotine or A $\beta 1-16$ were applied in extracellular solution at concentration of $100 \mu \mathrm{M}$ or $200 \mathrm{pM}$ respectively, using a glass pipette with a PDES-02I pneumatic drug ejection system (npi electronic, Tamm, Germany) (300 ms, 2 bar) controlled by the command protocol. The resistance of the puff pipette measured in bath solution was always $>3$ and $<5 \mathrm{M} \Omega$. In a different experiment, $A \beta 1-16$ or $A \beta 17-42$ or vehicle solution were applied to the bath solution at a final concentration of $200 \mathrm{pM}$ and $\alpha 7 \mathrm{nAChRs}$ currents were recorded following puff application of nicotine. Signals were digitized at $20 \mathrm{kHz}$ and filtered at $5 \mathrm{kHz}$. Leak subtraction was performed offline.

Hippocampal neurons used for whole-cell patch clamp recordings were grown for 14-18 days. Patch pipettes from borosilicate glass had a pipette resistance of 4-6 $\mathrm{M} \Omega$ using Sutter P97 puller (Sutter Instrument, Novato, California, USA). Recordings with the series resistance $\geq 20 \mathrm{M} \Omega$ were discarded from the analysis. Extracellular solution contained in mM: $145 \mathrm{NaCl}, 2.5 \mathrm{KCl}, 2 \mathrm{MgCl} 2,2 \mathrm{CaCl} 2,10$ HEPES, and 10 D-glucose (pH 7.4 adjusted with $\mathrm{NaOH}$ ). Intracellular solution for recording of miniature EPSC (mEPSCs) contained in mM: $140 \mathrm{~K}$-gluconate, $1 \mathrm{MgCl} 2$, $2 \mathrm{CaCl}$, 4 NaATP, 10 EGTA, 10 HEPES, and $2 \mathrm{Mg}$-ATP, 0.3 Na-GTP ( $\mathrm{pH} 7.2-7.3$, adjusted with $\mathrm{KOH}$ ). Miniature IPSCs were recoded using intracellular solution in $\mathrm{mM}$ : $118 \mathrm{KCl}, 9$ EGTA, 10 HEPES, $4 \mathrm{MgCl} 2,1 \mathrm{CaCl} 2,2 \mathrm{Mg}$ ATP, 0.3 Na-GTP, (pH 7.2-7.3 adjusted with KOH). For the recording of mEPSCs $1 \mu \mathrm{M}$ TTX, $25 \mu \mathrm{M}$ APV, and $10 \mu \mathrm{M}$
Bicu, were added to the bath solution to block Na-channels, NMDA-receptors and GABAA-receptors respectively. To isolate mIPSCs, $10 \mu \mathrm{M}$ CNQX were added to the bath solution to block AMPA receptors. The holding potential for mEPSCs and mIPSCs recordings neurons was -60 and $-70 \mathrm{mV}$, respectively. A $\beta 1-16(200 \mathrm{pM})$ were added to culture medium of cells kept at $35^{\circ} \mathrm{C} 1 \mathrm{~h}$ prior to experiment and were also present in the extracellular solution during the recording. BgTx $(50 \mathrm{nM})$ was added to the culture medium 30 min prior to the amyloid peptides. mEPSCs and mIPSCs (200 events per cell) were recorded $60 \mathrm{~s}$ after the establishment of whole-cell configuration and analysed using Mini Analysis Program (Synaptosoft, Decatur, Georgia, USA). Data were acquired at $22^{\circ} \mathrm{C}$, using an EPC10 double Patchclamp amplifier, filtered at $3 \mathrm{kHz}$ and sampled at $40 \mathrm{kHz}$ using Patch Master 2.32 software and analyzed by use of Fit Master software v2.69 (all from HEKA, Lambrecht, Germany). Cultures from at least three independent preparations were used for each condition.

\section{Calcineurin activity measurements}

Calcineurin activity was determined using the fluorimetric calcineurin activity assay kit (\#207007, Calbiochem) according to the manufacturer's instructions and the Clariostar (BMG) plate reader. Briefly, cortical neurons were grown for in six-well plates for 21 days. $1 \mathrm{~h}$ before treatments growth medium was changed to Tyrode's buffer (TB) (in $\mathrm{mM}: 120 \mathrm{NaCl}, 5 \mathrm{KCl}, 10$ glucose, $18 \mathrm{NaHCO}_{3}, 1 \mathrm{MgCl}_{2}$, $2.5 \mathrm{CaCl}_{2}, \mathrm{pH}$ 7.4) supplemented with $28 \mu \mathrm{M}$ choline. BgTx $(50 \mathrm{nM})$ was added $30 \mathrm{~min}$ after the medium change. $\mathrm{A} \beta$ peptides $(200 \mathrm{pM})$ and PNU-120596 $(3 \mu \mathrm{M})$ were added $1 \mathrm{~h}$ after medium change and kept for $1 \mathrm{hr}$ at $37{ }^{\circ} \mathrm{C}$ at $5 \%$ $\mathrm{CO} 2$ atmosphere. In total $2 \mathrm{~h}$ after medium change, cells in all wells were harvested in $150 \mu \mathrm{l}$ of kit lysis buffer with protease inhibitor cocktail. For each experiment three wells were pooled. The lysates were processed over Zeba spin column (\#89883, ThermoFisher Scientific) to remove free phosphate and exchange buffer to kit assay buffer. To calculate calcineurin specific activity, the $\mathrm{Ca} 2+$-independent phosphatase activity measured in the presence of EGTA was subtracted from the total phosphatase activity measured in lysates. Protein concentration in each lysate was determined using standard BCA assay and the calcineurin activity was corrected for total protein amounts in respective sample. Relative activities were normalized to the untreated control.

\section{Anti-synaptotagmin 1 Ab-CypHer5E imaging and analysis}

To label all recycling vesicles, primary rat hippocampal cultures (18-21 DIV) were incubated with anti Syt1-CypHer5E $\mathrm{Ab}$ for $1 \mathrm{~h}$ at $37^{\circ} \mathrm{C}$ in $\mathrm{TB}$ supplemented with $28 \mu \mathrm{M}$ choline. 
After loading, cells were washed twice with TB to remove excessive dye. Treatments were done as follows: A $\beta 1-16$ was applied $1 \mathrm{hr}$ prior to and during Syt1-CypHer5E Ab loading in TB supplemented with $28 \mu \mathrm{M}$ choline. BgTx $(50 \mathrm{nM})$ was applied 30 min before $A \beta 1-6$ and kept throughout the whole experiment. To inhibit calcineurin activity FK 506 $(1 \mu \mathrm{M})$ was added along with $\mathrm{A} \beta 1-16$ treatment. $\mathrm{A} \beta 1-16$ and inhibitors were kept in cells also during the imaging. The application of FK506 alone had no effect on Syt-CypHer5E release (not shown). For imaging, coverslips were placed on the base of a field stimulation chamber equipped with $10 \mathrm{~mm}$ spacing platinum electrodes (\#RC-49MFSH without perfusion, Warner Instrument, Hamden, Connecticut, USA) and imaged at RT in physiological TB supplied with $10 \mu \mathrm{M}$ CNQX, $50 \mu \mathrm{M}$ APV, $1 \mu \mathrm{M}$ bafilomycin $\mathrm{A} 1$ and $28 \mu \mathrm{M}$ choline on epifluorescence microscope (Nikon Eclipse Ti, Nikon Corporation), using an automated perfect focus system (PFS) and 60X/NA1.2 water-immersion objective (CFI Plan Apo VC, Nikon Corporation). To release the readily releasable pool (RRP), 40 APs were evoked by electric field stimulation ( $1 \mathrm{~ms}$ pulses of $70 \mathrm{~mA}$ ) applied by A 385 stimulus isolator (World Precision Instruments, Sarasota, Florida, USA) connected to a stimulus generator (\#STG-4008, Multi Channel Systems, Reutlingen, Germany). Subsequent to stimulations $\mathrm{TB}$ containing $60 \mathrm{mM} \mathrm{NH}_{4} \mathrm{Cl}$ was applied to achieve alkalization across all membranes. CypHer5E fluorescent dye was excited at $628 / 40 \mathrm{~nm}$ with a Led-HUB lamp (Omicron-laserage Laserprodukte $\mathrm{GmbH}$, Rodgau, Germany) and time-lapse images were acquired at the frequency of $1 \mathrm{~Hz}$ using Andor camera (Andor Technology) controlled by VisiView (Visitron System $\mathrm{GmbH}$ ) software in $2 * 2$ binning mode.

Data were exported as stack files (.stk) containing frames with $512 \times 512$ pixels of 16 -bit monochromatic intensity values. For data processing, files were converted to tagged image file format (Multipage-tiff) using ImageJ (National Institutes of Health) and loaded to MATLAB ${ }^{\circledR}$ to identify active boutons and fluorescence changes upon stimulation by custom-written scripts. A feature point detection algorithm [41] was implemented to automatically detect regions of interest (ROIs). In brief, coordinates of ROIs were identified on the averaged image formed from three frames prior to the first electrical stimulation. First, centroids of ROIs were determined as local fluorescence intensity maxima additionally exceeding an intensity threshold value set by distribution of intensity values. ROIs are represented as pixels circularly surrounding the detected centroids. Fluorescence intensity traces of individual ROIs were obtained by averaging fluorescence intensity from pixels within corresponding ROI in each frame. For background subtraction, background intensity value was determined on each frame by smoothing with a Gaussian filter and thresholding the grey level histogram to select dark pixels. The mean value over dark pixels was subtracted from the corresponding original frame. Dye bleaching was computationally compensated by modelling the effect with an exponential fit of a bleaching curve according to \{Hua, $2011 \# 1$ \}. Therefore, bleaching curve was constructed from averaged ROI derived traces. Within this mean curve, segments displaying a strong change in fluorescence upon stimulation were detected by a custom-written edge detection function returning positions of these segments as well as related change in fluorescence $\Delta F$. Detection is based on the second derivative to determine the edges within the curve. Finally, detected segments were cut out and remaining sections were assembled by adding the cumulative fluorescence difference of related stimulus. An exponential Eq. (1) modelled bleaching related decay in the mean curve. Numerical fit with MATLAB ${ }^{\circledR}$ built-in functions yielded in coefficient lambda $\lambda$.

$Y=a * \exp (\lambda * x)$

Finally, iterative deconvolution according to formula (2) corrected for bleaching with $\mathrm{I}_{\text {Measure }}(\mathrm{i})$ being the intensity value of the present curve at data point $i$ and $\mathrm{I}_{\text {corr }}$ being the corrected intensity value at data point.

$I_{\text {corr }}(i)=I_{\text {Measure }}(i)-\Sigma\left(\lambda * I_{\text {Measure }}(i)\right)$

Fluorescence traces were normalized by min-max feature scaling according to (3). Thereby $I_{\min }$ is related to the fluorescence intensity after $\mathrm{NH}_{4} \mathrm{Cl}$ alkalization and corresponds to the averaged values from the last three frames of a recording. Accordingly $I_{\max }$ is the baseline value prior to electrical field stimulations and corresponds to the averaged values derived from frames three to six.

$I^{\prime}=\frac{I-I_{\min }}{I_{\max }-I_{\min }}$

To exclusively evaluate active synaptic boutons that release synaptic vesicles upon electrical field stimulation, traces from individual ROIs were analysed to get precise positions and values of $\Delta \mathrm{F}$ upon stimulation. Therefore a modified algorithm based on the edge detection algorithm from bleaching correction was used. Invalid positions that were detected due to the high noise within individual traces were sorted out by passing the positions from the previously performed edge detection as template to the program. Finally, ROIs were characterized as active synaptic boutons if first or second $\Delta \mathrm{F}$ exceeds a threshold that was defined as the median of the $20 \%$ lowest $\Delta \mathrm{F}$ across all ROIs within the whole recording. Additionally, ROIs with less than four responses out of ten stimulations were excluded. Mean curve from active synaptic boutons was calculated and mean $\Delta \mathrm{F}$ upon each electrical was determined for each stimulation by performing edge detection algorithm again. Results were then exported as Excel file (Microsoft, Redmond, 
Washington, USA) for statistics and visualization in Excel and GraphPad Prism 8. All used codes are freely available on Github (https://github.com/EvaMWe/CypHer5E Imaging).

\section{Statistics}

Statistical analyses were performed using GraphPad Prism 8 (GraphPad Software, San Diego, California, USA). All data are normalized as described in graphs, expressed as mean \pm SEM in text and represented as 'Box-whiskers' showing the interquartile distance with median, minimum and maximal values and mean showed as + in plots. The statistical tests and numbers of cells (ICC, Syt1 Ab uptake assay, and electrophysiology data), number of wells from a 96-well plate $\left(\mathrm{Ca}^{2+}\right.$ data), coverslips (Syt1- CypHer5E data) and independent cultures preparation (qPCR data) analysed for each experiment are indicated in the respective figure legend and graphs. Statistical significances are showed as $* p<0.05, * * p<0.01, * * * p<0.001$.

Supplementary Information The online version contains supplementary material available at https://doi.org/10.1007/s00018-021-03835-5.

Acknowledgements We thank S. Müller, K. Elbert, J. Monti, I. Izydorczyk and the team of animal facility at PETZ Erlangen for excellent technical support, Cosima Rhein for providing qPCR protocols, N. Ziv for OpenView software, and P. Kaeser for CRE and $\triangle \mathrm{CRE}$ lentiviruses. This article contains data generated by $\mathrm{D}$. Anni during her $\mathrm{PhD}$ at the FAU. Data will be published in her PhD thesis on 29.05.2021.

Author contributions Conceptualization, project administration; writing - original draft: DA and AF; data curation: DA, EMW, JK, AF; formal analysis: DA, EMW, YEA, JK; funding acquisition: TH, AF; investigation: DA, EMW, DG, YEA, JK, MAA; methodology: DA, EMW, DG, YEA, JK, SZ, TH; AF; resources, supervision: TH, AF; software: EMW; visualization: DA, EMW, AF; writing - review and editing: all authors.

Funding Open Access funding enabled and organized by Projekt DEAL. This study was supported by DFG (270949263/GRK2162 and FE1335/3) and BMFB GeNeRARe (FZ 01GM1902B) to AF and DFG (HU 2358/1-1) to TH. YEA was supported by the Interdisciplinary Center for Clinical Research (IZKF) at the University Hospital of the University of Erlangen-Nuremberg (J74).

Availability of data and material Data and material are available upon reasonable request.

Code availability All used codes are available on Github (https:// github.com/EvaMWe/CypHer5E Imaging).

\section{Declarations}

Conflict of interest The authors have no competitive interests to declare.

Ethical aproval for experiemtns using animal material The experimetns invovlng animals in this study was approved by local animl welfare officer (FAU:TS12/2016 and TS13/2016) and in accordance with the European Directive 2010/63/EU and German animal welfare law.

Open Access This article is licensed under a Creative Commons Attribution 4.0 International License, which permits use, sharing, adaptation, distribution and reproduction in any medium or format, as long as you give appropriate credit to the original author(s) and the source, provide a link to the Creative Commons licence, and indicate if changes were made. The images or other third party material in this article are included in the article's Creative Commons licence, unless indicated otherwise in a credit line to the material. If material is not included in the article's Creative Commons licence and your intended use is not permitted by statutory regulation or exceeds the permitted use, you will need to obtain permission directly from the copyright holder. To view a copy of this licence, visit http://creativecommons.org/licenses/by/4.0/.

\section{References}

1. Abramov E, Dolev I, Fogel H, Ciccotosto GD, Ruff E, Slutsky I (2009) Amyloid-beta as a positive endogenous regulator of release probability at hippocampal synapses. Nat Neurosci 12:1567-1576

2. Alkondon M, Pereira EF, Cortes WS, Maelicke A, Albuquerque EX (1997) Choline is a selective agonist of alpha7 nicotinic acetylcholine receptors in the rat brain neurons. Eur J Neurosci 9:2734-2742

3. Brody DL, Magnoni S, Schwetye KE, Spinner ML, Esparza TJ, Stocchetti N, Zipfel GJ, Holtzman DM (2008) Amyloid-beta dynamics correlate with neurological status in the injured human brain. Science 321:1221-1224

4. Burrone J, Li ZY, Murthy VN (2006) Studying vesicle cycling in presynaptic terminals using the genetically encoded probe synaptopHluorin. Nat Protoc 1:2970-2978

5. Castro NG, Albuquerque EX (1995) Alpha-bungarotoxin-sensitive hippocampal nicotinic receptor-channel has a high-calcium permeability. Biophys J 68:516-524

6. Cecon E, Dam J, Luka M, Gautier C, Chollet AM, Delagrange P, Danober L, Jockers R (2019) Quantitative assessment of oligomeric amyloid beta peptide binding to alpha7 nicotinic receptor Br J Pharmacol 176:3475-3488

7. Cirrito JR, Yamada KA, Finn MB, Sloviter RS, Bales KR, May PC, Schoepp DD, Paul SM, Mennerick S, Holtzman DM (2005) Synaptic activity regulates interstitial fluid amyloid-beta levels in vivo. Neuron 48:913-922

8. Facci L, Skaper SD (2018) Culture of rodent cortical, hippocampal, and striatal neurons. Methods Mol Biol 1727:39-47

9. Fejtova A, Davydova D, Bischof F, Lazarevic V, Altrock WD, Romorini S, Schone C, Zuschratter W, Kreutz MR, Garner CC et al (2009) Dynein light chain regulates axonal trafficking and synaptic levels of Bassoon. J Cell Biol 185:341-355

10. Fogel H, Frere S, Segev O, Bharill S, Shapira I, Gazit N, O’Malley T, Slomowitz E, Berdichevsky Y, Walsh DM et al (2014) APP homodimers transduce an amyloid-beta-mediated increase in release probability at excitatory synapses. Cell Rep 7:1560-1576

11. Garcia-Osta A, Alberini CM (2009) Amyloid beta mediates memory formation. Learn Mem 16:267-272

12. Gronlien JH, Hakerud M, Ween H, Thorin-Hagene K, Briggs CA, Gopalakrishnan M, Malysz J (2007) Distinct profiles of alpha7 nAChR positive allosteric modulation revealed by structurally diverse chemotypes. Mol Pharmacol 72:715-724

13. Gu S, Matta JA, Lord B, Harrington AW, Sutton SW, Davini WB, Bredt DS (2016) Brain alpha7 nicotinic acetylcholine receptor assembly requires NACHO. Neuron 89:948-955 
14. Gulisano W, Melone M, Ripoli C, Tropea MR, Li Puma DD, Giunta S, Cocco S, Marcotulli D, Origlia N, Palmeri A et al (2019) Neuromodulatory action of picomolar extracellular Abeta42 oligomers on presynaptic and postsynaptic mechanisms underlying synaptic function and memory. J Neurosci 39:5986-6000

15. Haass C (2004) Take five-BACE and the gamma-secretase quartet conduct Alzheimer's amyloid beta-peptide generation. Embo J 23:483-488

16. Haass C, Kaether C, Thinakaran G, Sisodia S (2012) Trafficking and proteolytic processing of APP. Cold Spring Harb Perspect Med 2:a006270

17. Hampel H, Mesulam MM, Cuello AC, Farlow MR, Giacobini E, Grossberg GT, Khachaturian AS, Vergallo A, Cavedo E, Snyder PJ et al (2018) The cholinergic system in the pathophysiology and treatment of Alzheimer's disease. Brain J Neurol 141:1917-1933

18. Hick M, Herrmann U, Weyer SW, Mallm JP, Tschape JA, Borgers M, Mercken M, Roth FC, Draguhn A, Slomianka L et al (2015) Acute function of secreted amyloid precursor protein fragment APPsalpha in synaptic plasticity. Acta Neuropathol 129:21-37

19. Hua Y, Sinha R, Thiel CS, Schmidt R, Huve J, Martens H, Hell SW, Egner A, Klingauf J (2011) A readily retrievable pool of synaptic vesicles. Nat Neurosci 14:833-839

20. Jarrett JT, Berger EP, Lansbury PT Jr (1993) The carboxy terminus of the beta amyloid protein is critical for the seeding of amyloid formation: implications for the pathogenesis of Alzheimer's disease. Biochemistry 32:4693-4697

21. Jovanovic JN, Sihra TS, Nairn AC, Hemmings HC Jr, Greengard P, Czernik AJ (2001) Opposing changes in phosphorylation of specific sites in synapsin I during Ca2+-dependent glutamate release in isolated nerve terminals. J Neurosci 21:7944-7953

22. Kaeser PS, Deng L, Wang Y, Dulubova I, Liu X, Rizo J, Sudhof TC (2011) RIM proteins tether Ca2+ channels to presynaptic active zones via a direct PDZ-domain interaction. Cell 144:282-295

23. Kamenetz F, Tomita T, Hsieh H, Seabrook G, Borchelt D, Iwatsubo T, Sisodia S, Malinow R (2003) APP processing and synaptic function. Neuron 37:925-937

24. Kim SH, Ryan TA (2010) CDK5 serves as a major control point in neurotransmitter release. Neuron 67:797-809

25. Kraszewski K, Mundigl O, Daniell L, Verderio C, Matteoli M, De Camilli P (1995) Synaptic vesicle dynamics in living cultured hippocampal neurons visualized with CY3-conjugated antibodies directed against the lumenal domain of synaptotagmin. J Neurosci 15:4328-4342

26. Lasala M, Fabiani C, Corradi J, Antollini S, Bouzat C (2019) Molecular modulation of human alpha7 nicotinic receptor by amyloid-beta peptides. Front Cell Neurosci 13:37

27. Lawrence JL, Tong M, Alfulaij N, Sherrin T, Contarino M, White MM, Bellinger FP, Todorovic C, Nichols RA (2014) Regulation of presynaptic $\mathrm{Ca} 2+$, synaptic plasticity and contextual fear conditioning by a N-terminal beta-amyloid fragment. J Neurosci 34:14210-14218

28. Lazarevic V, Fienko S, Andres-Alonso M, Anni D, Ivanova D, Montenegro-Venegas C, Gundelfinger ED, Cousin MA, Fejtova A (2017) Physiological concentrations of amyloid beta regulate recycling of synaptic vesicles via Alpha7 acetylcholine receptor and CDK5/calcineurin signaling. Front Mol Neurosci 10:221

29. Lazarevic V, Schone C, Heine M, Gundelfinger ED, Fejtova A (2011) Extensive remodeling of the presynaptic cytomatrix upon homeostatic adaptation to network activity silencing. J Neurosci 31:10189-10200

30. Lois C, Hong EJ, Pease S, Brown EJ, Baltimore D (2002) Germline transmission and tissue-specific expression of transgenes delivered by lentiviral vectors. Science 295:868-872

31. Marra V, Burden JJ, Thorpe JR, Smith IT, Smith SL, Hausser M, Branco T, Staras K (2012) A preferentially segregated recycling vesicle pool of limited size supports neurotransmission in native central synapses. Neuron 76:579-589

32. Masters CL, Simms G, Weinman NA, Multhaup G, McDonald BL, Beyreuther K (1985) Amyloid plaque core protein in Alzheimer disease and Down syndrome. Proc Natl Acad Sci USA 82:4245-4249

33. Morley JE, Farr SA, Banks WA, Johnson SN, Yamada KA, Xu L (2010) A physiological role for amyloid-beta protein:enhancement of learning and memory. J Alzheimers Dis 19:441-449

34. Mura E, Zappettini S, Preda S, Biundo F, Lanni C, Grilli M, Cavallero A, Olivero G, Salamone A, Govoni S et al (2012) Dual effect of beta-amyloid on alpha7 and alpha4beta2 nicotinic receptors controlling the release of glutamate, aspartate and GABA in rat hippocampus. PLoS One 7:e29661

35. Portelius E, Andreasson U, Ringman JM, Buerger K, Daborg J, Buchhave P, Hansson O, Harmsen A, Gustavsson MK, Hanse E et al (2010) Distinct cerebrospinal fluid amyloid beta peptide signatures in sporadic and PSEN1 A431E-associated familial Alzheimer's disease. Mol Neurodegen 5:2

36. Portelius E, Price E, Brinkmalm G, Stiteler M, Olsson M, Persson R, Westman-Brinkmalm A, Zetterberg H, Simon AJ, Blennow K (2011) A novel pathway for amyloid precursor protein processing. Neurobiol Aging 32:1090-1098

37. Portelius E, Westman-Brinkmalm A, Zetterberg H, Blennow K (2006) Determination of beta-amyloid peptide signatures in cerebrospinal fluid using immunoprecipitation-mass spectrometry. $\mathrm{J}$ Proteome Res 5:1010-1016

38. Puzzo D, Privitera L, Fa M, Staniszewski A, Hashimoto G, Aziz F, Sakurai M, Ribe EM, Troy CM, Mercken M et al (2011) Endogenous amyloid-beta is necessary for hippocampal synaptic plasticity and memory. Ann Neurol 69:819-830

39. Puzzo D, Privitera L, Leznik E, Fa M, Staniszewski A, Palmeri A, Arancio O (2008) Picomolar amyloid-beta positively modulates synaptic plasticity and memory in hippocampus. J Neurosci 28:14537-14545

40. Richter MC, Ludewig S, Winschel A, Abel T, Bold C, Salzburger LR, Klein S, Han K, Weyer SW, Fritz AK et al (2018) Distinct in vivo roles of secreted APP ectodomain variants APPsalpha and APPsbeta in regulation of spine density, synaptic plasticity, and cognition. EMBO J 37

41. Sbalzarini IF, Koumoutsakos P (2005) Feature point tracking and trajectory analysis for video imaging in cell biology. J Struct Biol 151:182-195

42. Seguela P, Wadiche J, Dineley-Miller K, Dani JA, Patrick JW (1993) Molecular cloning, functional properties, and distribution of rat brain alpha 7: a nicotinic cation channel highly permeable to calcium. J Neurosci Off J Soc Neurosci 13:596-604

43. Selkoe DJ (2001) Alzheimer's disease: genes, proteins, and therapy. Physiol Rev 81:741-766

44. Tsuriel S, Geva R, Zamorano P, Dresbach T, Boeckers T, Gundelfinger ED, Garner CC, Ziv NE (2006) Local sharing as a predominant determinant of synaptic matrix molecular dynamics. PLoS Biol 4:1572-1587

45. Verstegen AM, Tagliatti E, Lignani G, Marte A, Stolero T, Atias M, Corradi A, Valtorta F, Gitler D, Onofri F et al (2014) Phosphorylation of synapsin I by cyclin-dependent kinase- 5 sets the ratio between the resting and recycling pools of synaptic vesicles at hippocampal synapses. J Neurosci 34:7266-7280

46. Vigo-Pelfrey C, Lee D, Keim P, Lieberburg I, Schenk DB (1993) Characterization of beta-amyloid peptide from human cerebrospinal fluid. J Neurochem 61:1965-1968

47. Wang HY, Lee DH, D'Andrea MR, Peterson PA, Shank RP, Reitz AB (2000) beta-Amyloid(1-42) binds to alpha7 nicotinic acetylcholine receptor with high affinity. Implications for Alzheimer's disease pathology. J Biol Chem 275:5626-5632 
48. Wang HY, Lee DH, Davis CB, Shank RP (2000) Amyloid peptide Abeta(1-42) binds selectively and with picomolar affinity to alpha7 nicotinic acetylcholine receptors. J Neurochem 75:1155-1161

49. Wang Y, Xiao C, Indersmitten T, Freedman R, Leonard S, Lester HA (2014) The duplicated alpha7 subunits assemble and form functional nicotinic receptors with the full-length alpha7. J Biol Chem 289:26451-26463
Publisher's Note Springer Nature remains neutral with regard to jurisdictional claims in published maps and institutional affiliations. 